\title{
Market interaction and stratified production
}

\section{Competition, cartel formation and monopolisation}

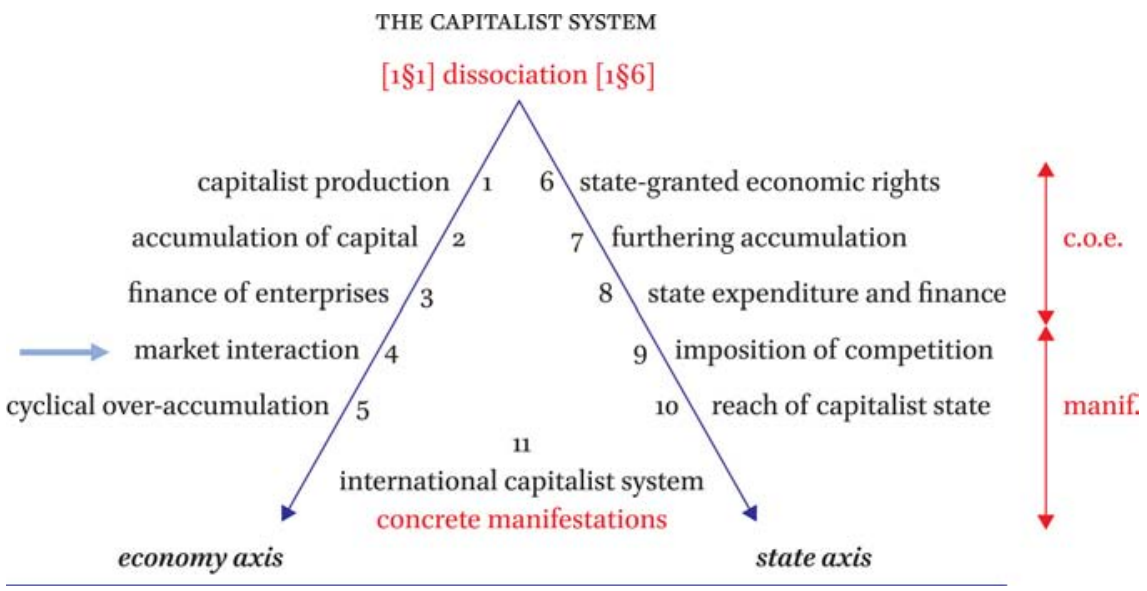

Note: 'c.o.e.' abbreviates conditions of existence and 'manif.' manifestations.

\section{Contents}

Introduction 201

Division 1. The market and the stratified structure of production $\quad 203$

$4 \S 1 \quad$ Market interaction 203

$4 \S 2$ Inter-market interaction: the tendency to equalisation of average inter-sector rates of integral profit 205

$4 \S 3 \quad$ Intra-market interaction: the tendency to uniform prices 207

$4 \S 4$ Stratification of enterprises and plants 208

$4 \S 5$ Instrumentality of the form of market interaction 214

Division 2. Deflationary price competition $\quad 214$

$4 \S 6$ Stratified price competition: devalorisation via a decreasing 'unit monetary value of labour' $\quad 215$

$4 \S 7 \quad$ Devalorisation accounted on devalued capital 220

$4 \S 8$ Derived price decrease and derived devaluation of capital 220

$4 \S 9 \quad$ Generalised price competition and the pace of technical change: price deflation and the tendency to stagnation $\quad 222$

(C) GEERT REUTEN, 2019 | DOI:10.1163/9789004392809_006

This is an open access chapter distributed under the terms of the prevailing CC-BY-NC-ND License at the time of publication. 
Division 3. Inflationary 'structural overcapacity competition' 225

$4 \S 10$ Overcapacity competition: introduction 225

$4 \S 11$ The monetary condition of an inflationary constellation: banks' PVF and the 'unit monetary value of labour' 227

$4 \S 12$ Stratified structural overcapacity competition $\quad 228$

Division 4. The tendency to cartel formation 234

$4 \S 13$ The tendency to cartel formation: stagnant innovation 234

Division 5. The tendency to oligopolisation and monopolisation 236

$4 \S 14$ The tendency to centralisation of capital $\quad 237$

Summary and conclusions $\quad 239$

List of figures chapter $4 \quad 241$ 


\section{Introduction}

Chapters 1-3 presented the necessary conditions of existence of the capitalist economy (with the state yet bracketed). Chapters 4 and 5 (the last two chapters of Part One) present no further conditions of existence, but rather concrete manifestations of the earlier exposition (see also the pyramid figure at the opening of the chapter).

Manifestations have three main characteristics. First, they are implications of the necessary moments - implications that most often have a 'tendency' character. Second, manifestations are the culmination of the synthetic exposition - building on that of the grounding moments. Third, whereas those grounding moments reveal the reproductive strength of the capitalist system, the implications of the simultaneous interaction of these grounding moments are also expressed in concrete manifestations that thus reveal not only reproductive strength but also reproductive vulnerability.

Chapter 4 introduces the market interaction between enterprises into the exposition. Even though the exposition of Chapters 1-3 was prompted by the commodification and the transactions that are necessary to overcome the initial bifurcation between households and private units of production (1D1), the term 'market' has hardly been mentioned up to this point. This has been due to the method of exposition, which starts by seeking the connection between phenomena in the elements that unite them into a totality, that is, the totality of the capitalist system, and so far the capitalist economy.

Until now the exposition treated the totality of the capitalist economy in a way that combined a macroeconomic emphasis with the actions of the 'average capitalist enterprise'. Broadly the focus was thus on, first, the interconnection between enterprises and labour, and second, the interconnection between enterprises and banks. Now, in that light, the exposition in the current chapter focuses on the interconnecting interaction between enterprises.

In this chapter the market interaction between enterprises is not presented from the perspective of an individual enterprise (the starting point of much of orthodox economics), but rather from the perspective of the constellation of enterprises in one sector (branch) of production. The central concept throughout the chapter is the 'stratification of enterprises' in a sector (introduced in Division 1). As we will see, this concept is related to the technique of production adopted.

Analytically the form of market interaction between enterprises may be classified along a continuum of rivalrous competition on the one end, and - via cartel formation - monopolisation on the other. The position on that continuum 
SCHEME 4.1 Market interaction and the stratified structure

of production: competition cartel formation,

oligopolisation and monopolisation (outline

Chapter 4)

Production, Accumulation, and Finance

[Chapters 1-3]

.M.

the market and the stratified structure of production

tendencies of enterprises' market interaction $[4 \mathrm{D} 1]$

.mm.

two general alternate modes of manifestation

(each with the scale of $\mathrm{K}$ implicit)

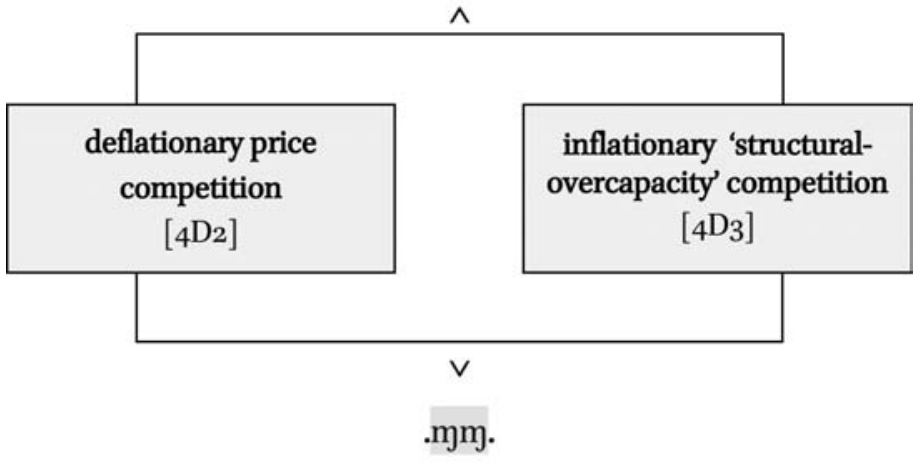

two particular coexisting modes of manifestation

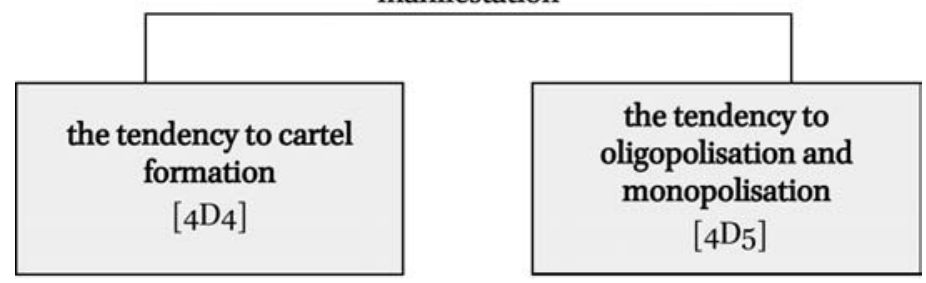

Legend

.M. concrete manifestation

. $\mathrm{mm}$. mode of manifestation 
would then seem to be contingent and each such position might be analytically modelled (this is the main approach in orthodox economics).

In the exposition of this chapter, the forms of market interaction - competition, cartels, oligopoly and monopolisation - are presented as being predicated on the stratified structure of production in particular sectors. This structure is again predicated on the accumulation of capital as conditioned by technical change. (Divisions 2-5.)

In comparison with the competitive interaction (Divisions 2-3), relatively little space is devoted to cartel formation, oligopolisation and monopolisation (Divisions 4-5). This is not because the latter are of minor importance. On the contrary. It is rather that their exposition is less complicated than that of competition - noting here already that the latter is not presented from the perspective of equilibrium, nor of 'perfect competition'.

The two divisions on competition are associated with price deflationary $\left(4 \mathrm{D}_{2}\right)$ and, alternatively, price inflationary $\left(4 \mathrm{D}_{3}\right)$ constellations. It will be seen in the latter division that 'deflation' or 'inflation' are not purely monetary phenomena; rather these result from the 'real' interaction of enterprises, together with their monetary accommodation by banks. (Again, monetary matters are not a negligible 'veil', but of key importance).

The chapter starts with an exposition of 'market interaction' in general (independent of its particular forms). Here we will see in particular how this interaction is grounded in the structure of production (Division 1).

Scheme 4.r outlines the systematic of the present chapter.

\section{Division 1. The market and the stratified structure of production Tendencies of enterprises' market interaction}

This division presents the previous exposition's (Chapters 1-3) general manifestation in the 'market interaction' of enterprises - independent of its particular modes of manifestation presented in the rest of the chapter. As indicated in the Introduction, like the following divisions it provides no conditions of existence of the earlier exposition.

\section{$4 \S 1 \quad$ Market interaction}

Enterprises are first of all interconnected as units that have the same aim, that is, the production of surplus-value as measured by the rate of integral profit $\left(1 \S 13_{-}^{-}\right.$ $1 \S 14)$, along with production on an increasing scale $(2 \mathrm{D} 1)$. This is the primary determinant of the enterprises' similarity. However, enterprises may also be similar insofar as they are engaged in the production of a similar physical product and in similar transactions, through which they are part of 'a market'. 
In going for the same aim enterprises may, in principle, engender competition, cartels or monopolisation. These are three forms of what will be called the 'market interaction' of enterprises. In this first division, I present this market interaction in general - applying to each of these three forms. Market interaction (as competition, cartels or monopolisation) is the enterprises' processes of trade through which they, directly or indirectly, force the determinants of the capitalist system upon one another and upon themselves. ${ }^{1}$

Whereas enterprises have their capital necessarily invested in particular sectors of production, and so operate in particular markets, they are nevertheless merely units of one and the same thing - capital - that strive between, or with, each other for one and the same thing: capital accumulation. In this respect production enterprises are no different from banks or entities engaged in nonbanking financial or property businesses, or combinations of these. ${ }^{2}$ For the market perspective of this chapter, therefore, these sectors and their enterprises are treated alike. ${ }^{3}$

For the purposes of this chapter, the current division's exposition of market interaction will be restricted to its three main moments: first, inter-market rates of integral profit ( $4 \S 2)$; second, intra-market prices $(4 \S 3)$; and a third moment, 'stratified production', which is a consequence of these first two moments $(4 \S 4)$.

4§1-a Explication. Effective demand and supply

This chapter presents the enterprises' market interaction. Macroeconomic effective demand, and more specifically its effect on the validation of surplusvalue, was presented in ${ }_{3} \mathrm{D}_{5}$. How this demand is allotted to specific microeconomic sectors of production cannot be determined theoretically. We can say no

1 In terms of our exposition, these are the necessary determinants presented in Chapters 13. The last sentence paraphrases Marx, regarding competition, in his Grundrisse (1973a \{ms ${ }_{1857-58\}}$, p. 651): 'Competition merely expresses as real, posits as an external necessity, that which lies within the nature of capital; competition is nothing more than the way in which the many capitals force the inherent determinants of capital upon one another and upon themselves.' Thus, what Marx writes about 'competition', I generalise to 'interaction' (including competition).

2 This is so even if, as we have seen ( $3 \S_{1}$ and Figure $\left.3.2 b\right)$, 'banks as pure financiers' are nonproduction enterprises that do not produce surplus-value and are, for the growth of their finance capital, parasitically dependent on the production of surplus-value in production enterprises.

3 For current purposes, the terms 'market' and 'sector' are used interchangeably. However, the term sector is usually more appropriate in reference to production (as in 'sector of production'). 
more about it than that enterprises will try to attract demand via the design of their products and via (broadly) advertisement, which below is treated as part of the production costs. Given that, the effective demand for sector-products is taken as given, at least for the horizon of the investments in fixed means of production.

4§1-b Addendum. 'Competition' in economics dictionaries and textbooks

Although this division is about market interaction in general, it seems useful to say something about the term 'competition' now rather than later. Mainstream economics does not seem to have a general name for what I call 'market interaction' (or it should be 'market behaviour'). It tends to take cartels and monopolisation, including forms of collusion, as a 'deviation' from 'competition'. Nevertheless, no textbook of economics that I have seen provides a succinct definition of 'competition'.

However, in a paper specifically devoted to the matter, Saviotti and Krafft (2004, p. 2) write:

'we have come today to a rather consensual definition of competition ... Competition is taken to mean that range of actions aimed at ensuring the realization of the choices of a given firm while restraining at the same time the sphere of actions of its rivals. Competition is a process of rivalry between firms which takes the form of contests within existing markets (intra-industry competition), and the form of potential entry into new areas (inter-industry competition). Competition includes rivalry in terms of price, but also in terms of altered or improved techniques of production or products ...'

\section{$4 \S 2$ Inter-market interaction: the tendency to equalisation of average inter-sector rates of integral profit}

The dominance of monetary valorisation over the technical labourprocess $\left(\mathrm{ID}_{5}, 1 \S 11\right)$ entails that enterprises are indifferent to the particular output produced, an indifference that we have seen to be expressed in the measure of the rate of integral profit, omega $\left(\mathrm{AD}_{5}, 1 \S 13\right)$.

Because integral profit is the internalised external driving force of enterprises, capital valorised and validated in one sector tends to flow to another one when its owner expects a higher rate of integral profit from that operation. This flow will affect supply. Because a change in supply will have, ceteris paribus, an inverse effect on prices and profits - the inter-market interaction thereby establishes a tendency to equalisation of average inter-sector (i.e. inter-market) rates of integral profit (TERP). (This is indeed a tendency. In $4 \mathrm{D}_{5}$ we will see how it 
is counteracted by tendencies to oligopolisation and monopolisation). We will see in $4 \S 4$ why the qualification of 'average' inter-sector rates of profit is significant.

\section{$4 \S 2-\mathrm{a} \quad$ Explication. Status of tendencies}

Much of the current division runs in terms of tendencies. See $2 \S 12$-a for the status of tendencies. Recall that a tendency is the generation of a particular form of an entity or the particular quantitative expression of an entity, this generation being predicated on certain forces or compulsions. In $4 \S 2$ this 'entity' is a rate of profit. A tendency may be counteracted by other tendencies, or by other lower level complexities. (A standard example from physics is the (tendency) law of gravity. Because that tendency law is counteracted by other tendencies we may, for example, feel fairly safe to sleep or work on the 7 th floor of a building). See the General Appendix A§14 for a more elaborative account of tendencies.

4§2-b Amplification. Equalisation of rates of profit via 'restructuring of capital'

The process of effectuation of the tendency to equalisation of average intersector rates of profit (TERP, $4 \S 2$ ) is a gradual one. It is concretised as a 'restructuring of capital' (вос), which encompasses two major phases. The first one involves the liquidation of existing plants or divisions of an enterprise - either by selling them and/or by the non-replacement of depreciated means of production. The second phase is that of a gradual investment in a new sector of production, or, far more likely, that of taking over an enterprise (or a division of it) in a new sector, whence we have conglomerate take-overs, followed by investment in the new sector of production. ${ }^{4}$ The two phases may also be combined in processes of conglomerate merging of enterprises, together with a shift in investment from one to another part of the conglomerate. This type of restructuring of capital, that is, inter-sector 'TERP-associated ROC', is one that takes place rather continuously even if unevenly.

This 'restructuring of capital' is one of two modes of Roc. In Chapter $5(5 \S 8-$ $5 \S 9)$ a second mode will be presented, which is connected with the business cycle.

4 The term 'conglomerate' refers to enterprises having vested interests in more than one sector. 


\section{$4 \S 3 \quad$ Intra-market interaction: the tendency to uniform prices}

For the concept of a market to make sense, we must analytically start from a considerable degree of similarity between the commodities traded - so making up a market (see Explanation $4 \S 3-\mathrm{a}$ ). Given the similarity of the physical outputs - including services - of a collection of enterprises $(4 \S 1)$, intra-market interaction is generally determined as price setting in reaction to that interaction. Starting off from any prevailing modal price in a market, there are analytically and practically two positions.

The first position is that of selling above the modal price. However, enterprises are compelled to continuously (rather than accidentally) realise the value produced. Therefore, even if in some period an enterprise were to accidentally be in a position to sell above the modal market price, such sales would tend to be declined, as it would have the effect of repelling buyers in a subsequent period.

The second position is that of selling below or at the (current) modal price. decline Because selling below the modal price would affect profits negatively, the individual enterprise has no interest in doing this, unless it is currently producing at overcapacity. In the absence of overcapacity then, prices will tend to stabilise at the existing level. In the case of overcapacity, and at a given effective demand, it does make sense to decrease the price. ${ }^{5}$ This implies that other enterprises will be burdened with overcapacity. The price then tends to establish at the uniform level at which the overcapacity is (pro rata the enterprises' capacity) evenly distributed.

Market interaction, therefore, establishes a tendency towards uniform prices in a market (TUP). (See also the one but last footnote on product differentiation.)

\begin{tabular}{|c|c|}
\hline $\begin{array}{l}\text { inter-market interaction } \\
\text { tendency to equalisation of average } \\
\text { inter-sector rates of integral profit } \\
{[\mathrm{TERP} ; 4 \S 2]}\end{array}$ & $\begin{array}{l}\text { intra-market interaction } \\
\text { tendency to uniform prices } \\
\qquad[\mathrm{TUP} ; 4 \S 3]\end{array}$ \\
\hline & \\
\hline $\begin{array}{l}\text { structure } \\
\text { stratification }\end{array}$ & $\begin{array}{l}\text { tion: } \\
\text { ises }[4 \S 4]\end{array}$ \\
\hline
\end{tabular}

5 When an enterprise produces at overcapacity, the profitability of a price decrease will depend on its effect on demand (the price 'elasticity'). 
4§3-a Explication. Intra-market interaction and product differentiation The main text stated that for the concept of a market to make sense, we must analytically start from a considerable degree of similarity between the commodities traded - thereby establishing a market. For both the actors and the economist studying markets, a 'market' is ultimately a relative matter depending on the particular courses of action or the problem at hand. Some product differentiation is often a factor in intra-market interaction. At some grade of differentiation it is useful to consider a market as partitioned or split off (and conversely, two markets as integrated). Theoretically and practically, we then have the inter-market determinant of the TERP $(4 \S 2)$. However, to the extent that product differentiation is increasingly the main focus, we either lose the concept of a market, or each individual enterprise must be considered as a monopolist. I think that in both analytical and practical terms, the latter approach is not a fruitful one.

\section{$4 \S 4 \quad$ Stratification of enterprises and plants}

\section{$1 \quad$ Interaction as reinforcing technical change}

The articulation of the two main tendencies of market interaction (TERP and TUP, $4 \S 2-4 \S 3$ ) means that the rate of integral profit of any enterprise comes to depend on its production process for any output: the reduction of the costs of production (given the input prices) and increase in the value-productivity of labour. These are determined by the valoro-technique of production adopted, together with the management of the power of labour as engendering increase in the productivity of labour $(2 \S 3)$. (Having stressed the dual character of techniques, from now on I will simply use the term 'technique' instead of valoro-technique.) The interaction of enterprises therefore reinforces and reproduces more concretely the compulsion to the accumulation of capital in new techniques of production $(2 \S 3-2 \S 4)$.

In the remainder of this section, and in most of this chapter, I build on the similarity of the products sold on a market $(4 \S 3 ; 4 \S 3-\mathrm{a})$. Hence the focus for techniques is on the process (as in 'process competition') rather than on the product (as in 'product competition'). This is the most transparent case for the interconnection of production and the market; product innovation is just a more complicated case, including market strategic considerations, which might in principle be incorporated in the framework below.

Stratification of enterprises refers to sectors of production being composed of not technically uniform, but rather technically heterogeneous enterprises, 
as explained below. Because, concretely, the technique refers to a 'plant', and because large enterprises tend to be composed of several divisions and 'plants' each with - at least internally - separated accounts, I will refer to this plant level of the enterprise. ${ }^{6}$

The investment of capital in new plants incorporating new techniques of production tends to be a discrete lumpy' process. ${ }^{7}$ In any case, the enterprise that successfully initiates a new technique of production secures a rate of profit above that for the existing enterprises (plants) in the sector. The consequent threat of price competition by the initiating enterprise, and the necessity for continuous valorisation, might seemingly compel the other enterprises to follow suit. ${ }^{8}$ However, because each enterprise is burdened with the fixed costs of its already accumulated capital, it will only scrap old plants when a new technique offers net profits ('net' that is, taking into account the costs of scrapping old plants) greater than the profits on its existing plant.

In other words, the preservation of capital already accumulated may prevent immediate moves towards investment in new-technique and maximum rate of profit plants. ${ }^{9}$ Scrapping of plants is only enforced when prices no longer cover prime costs. ${ }^{10}$ Before that, the scrapping of plants in favour of investment in new ones is determined by, first, the difference in rates of profit on the investment in an already existing plant, and on that in a new plant (inclusive of the capital foregone because of scrapping); and second, by the availability of finance. ${ }^{11}$

6 I will restrict myself to this one term 'plant'. For financial or commercial enterprises, 'plant' refers to the establishments or branches of such enterprises, i.e. those with at least internally separated accounts.

7 Next to these lumpy investments there may be, additionally, more continuous investments. Note that in the small business sector and in parts of the services sector, the (lumpy) 'plant' aspect of investment is only moderately dominant or sometimes even negligible. (To the extent that this is, contingently, inherent to a sector of production, this applies to the configuration set out in $4 \mathrm{D}_{4}$.)

8 This is the mainstream neoclassical equilibrium idea.

9 I am drawn into this way of presentation by the conventional neoclassical static equilibrium analysis of this matter, wherein the rate of profit is identified with the 'physical' plant-rate of profit. Note also that, in this chapter, interaction, and later on competition, should not be conceived of as neoclassical 'perfect'. Salter (1960) has shown that in the case of neoclassical perfect competition, capital would always immediately move to the new-technique plant.

10 'Prime costs' are the costs exclusive of those of fixed means of production.

11 This implies that a maximum rate of profit can only be gained by fully amortised plants. The conceptualisation here and in the remainder of this section differs from neoclassical vintage models (discussed in $4 \S 4$-b). 
Since, therefore, plants embodying new technology will in general not be immediately adopted by all enterprises, each sector of production tends to be composed of a stratification of plants dated according to technique, cost of production, value-productivity of labour and a resulting stratification of rates of integral profit (see Figure 4.2). ${ }^{12}$ The difference in these aspects between the top and the bottom of the stratification is called the range of the stratification. Later we will see that the degree of this range depends on the speed of technical change $(4 \S 13)$.

Recall my claim in the first sentence of this subsection. I do not claim that enterprises in all markets are so technically heterogeneous for the concept of stratification to make sense. However, I do claim that it applies for the economy on average. In the remainder of this chapter, I merely focus on the sectors that are clearly stratified.

\section{4§4-a Explication. Stratification and scrapping of plants}

The concept of stratification implies that at each point in time, enterprises within the same sector are physically non-identical (this may go without saying for non-economists; however, economists educated within the standard models of neoclassical economics are trained to see physical identity as the starting point for analysis). The focuses for the non-identity are the characteristics indicated at the end of $4 \$ 4$ : technique; costs; value-productivity of labour; and rate of integral profit. The reason for this non-identity is that enterprises will introduce new techniques of production only when these are expected to result in a higher rate of profit in comparison with capital accumulated in existing plants. However, preservation of capital already accumulated may prevent immediate moves towards investment in new-technique and maximum rate of profit plants. Therefore capital tends to be stratified according to technique, cost of production, value-productivity of labour and resulting rates of profit $(4 \S 4)$, as visualised in Figure 4.2. The oldest plant within a sector is indicated by the number 1 , while the most recently invested plant is indicated by the number $\mathrm{n}$.

12 If rates of profit are calculated over the lifetime of an asset, and if there were such a thing as perfect foresight, then calculated rates of profit might be equal. However, this does not affect the argument (see also $4 \S 6$ on devalorisation). The exposition in this chapter highlights that the state of the economy conceptualised is generally not one of equilibrium, nor is it one of 'perfect competition'. 
FIGURE 4.2 Stratification of plants

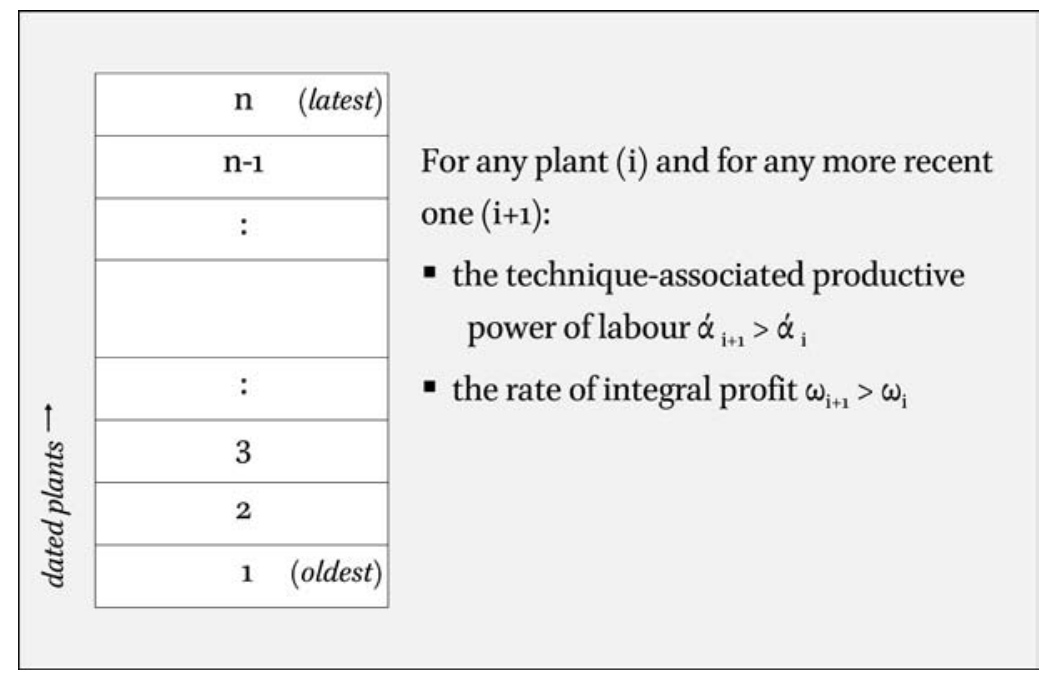

Recall from $1 \S 14$ the equations for the integral rate of profit $(\omega)$ and for production $(\mathrm{X})$, which are now applied to the microeconomic plant level (suffix i). All variables in the four equations below refer to time $(\mathrm{t})$ - time subscript omitted to avoid cumbersome notation.

$$
\omega_{\mathrm{i}}=\Pi_{\mathrm{i}} / \mathrm{K}_{\mathrm{i}}=\left[\mathrm{m}_{\mathrm{i}} \mathrm{L}_{\mathrm{i}}^{\alpha i \mathrm{i}}-(\mathrm{wL})_{\mathrm{i}}\right] / \mathrm{K}_{\mathrm{i}}
$$

Recall also that $\alpha$ denotes the technique-associated productive power of labour, and $\ddot{t}$ the intensity of labour. Whereas in Chapter 2 the primary focus was on the latter, the primary focus in the current chapter will be on $\alpha$. Although the current chapter does not exclude variations in intensity, it may be helpful for the reader to assume $\ddot{i}$ to be constant throughout the chapter.

For each plant we have running material costs $\left(\mu \mathrm{K}_{\mathrm{i}}\right)$ and a depreciation of fixed means of production $\left(\delta \mathrm{K}_{\mathrm{i}}\right)$. Thus we have for the plant output $\left(\mathrm{X}_{\mathrm{i}}\right)$ :

$$
\mathrm{X}_{\mathrm{i}}=\delta \mathrm{K}_{\mathrm{i}}+\mu \mathrm{K}_{\mathrm{i}}+\mathrm{wL}_{\mathrm{i}}+\Pi_{\mathrm{i}}
$$

Then any scrapping of plants is only enforced when their returns $\left(\mathrm{pq}_{\mathrm{i}}\right)$ outrun their 'prime costs' $\left(\mu \mathrm{K}_{\mathrm{i}}+\mathrm{wL}_{\mathrm{i}}\right)$, i.e.:

$$
\mathrm{pq}_{\mathrm{i}} \leq \mu \mathrm{K}_{\mathrm{i}}+\mathrm{wL}_{\mathrm{i}}(\text { returns } \leq \text { 'prime costs') }
$$

Thus treating the costs of the fixed means of production as a complete loss, the plant(s) at the bottom of the stratification may ultimately keep on producing until this point.

However, rather than the complete loss case, we may suppose the scrapvalue of a plant, or its liquidation value, to be $\mathrm{LV}_{\mathrm{i}}$. Suppose that there are no obstacles of finance, technique, etc., so that any one plant at the bottom could in principle be lifted to the top (' $n$ ', hence $K_{n}$ ), then the simple decision criterion would be: 
$\Pi_{\mathrm{n}} /\left(\mathrm{K}_{\mathrm{n}}-\mathrm{LV}_{\mathrm{i}}\right)>\left[\mathrm{pq}_{\mathrm{i}}-\left(\mu \mathrm{K}_{\mathrm{i}}+\mathrm{wL}_{\mathrm{i}}\right)\right] / \mathrm{LV}_{\mathrm{i}}$

To the extent that $\mathrm{LV}_{\mathrm{i}}$ is 'small', then - even if in 4.4 the $\mathrm{LHS}>\mathrm{RHS}^{13}$ - it may be profitable to keep the bottom plant going along with an investment at the top by the same enterprise. Equation (4.4) presents the simple idea. A more sophisticated comparison would go in terms of the discounted profit flow of each alternative.

(In most markets, there is some degree of product differentiation. We could make this part of the stratification, whence there may be price differences that are reflected in the divergent rates of profit. However, for simplification this is neglected here.)

Figure 4.2 is the general basis for the entirety of this chapter. The following divisions set out specifications.

\section{4§4-b Addendum. Stratification and vintage models}

Conventional neoclassical general equilibrium theories assume 'small' homogeneous plants, or firms, engaged in atomistic competition. It is hard to understand what would then keep competition going. Indeed, that conception of competition is highly ambiguous. As each unit is a perfect copy of every other, no more than comparative static states (differing from each other only to the extent that exogenous variables differ) can be described (see Blaug 2001). Such a conception may be traced back to the lack of differentiation between homogeneous capital as value and the heterogeneous embodiment of capital in a technical sense (that is, in our terminology, the internally bifurcated form of capitalist production).

However, neoclassical 'vintage models' are less simplified (see Solow 1970, ch. 3; the seminal references are: Johansen 1959; Salter 1960; Kaldor and Mirrlees 1962; Solow, Tobin, von Weizäcker and Yeari 1966; and Cass and Stiglitz 1969). One main difference from the concept of stratification as presented in $4 \S 4$ is that in the neoclassical conception, the obsolescence of plants is determined by the real wage (wage costs exceeding the average labour-productivity on a plant), rather than by the addition of plants to the stratification, introducing new cost-reducing techniques of production, and the resulting price decrease and/or overcapacity (see $4 \S 6$ ).

The notion of the extra profits gained by the enterprise (plant) at the top of the stratification is closely related to Schumpeter's notion of temporary monopoly profits accruing to the first enterprise to innovate, which are gradually eroded as the innovation diffuses through the industry and even the economy (see, e.g., Schumpeter 2003 [1943]).

LHS: left hand side; RHS: right hand side. 
4§4-c Addendum. Earlier work on stratification

I first set out the concept and a fairly simple model of stratification in Reuten and Williams 1989 (Chapters 4-5) and in Reuten 1991. At that time I used the concept and model particularly in the context of a theory of the business cycle and a particular type of technical development (a type characterised by an increasing capital-labour ratio), even if I already noted then that the scope of the model is wider than that context. A similar notion was adopted by Brenner (1998, e.g., p. 24ff.). I have now explicitly generalised the model to characterise market interaction in general $(4 \S 4)$ competition $\left(4 \mathrm{D}_{2}\right.$ and $\left.4 \mathrm{D}_{3}\right)$, cartels $\left(4 \mathrm{D}_{4}\right)$, and oligopolistic and monopolising interaction $\left(4 \mathrm{D}_{5}\right)$.

4§4-d Addendum. Stratification, capital-labour ratios and the tendential equalisation of average inter-sector rates of integral profit - a note on marxian political economy

A concept of a stratified structure of production within sectors is implicit in Marx's notion of the development of the technique-associated 'productive power of labour' as giving rise to intra-sector divergent 'potencies of labour' $\left(m y L_{i}^{\alpha}\right) \cdot{ }^{14}$ Especially to the extent that new techniques would entail an increasing capital-labour ratio $(\mathrm{K} / \mathrm{L})$, an increasing $\mathrm{L}^{\alpha}{ }_{\mathrm{i}}$ along with it is a precondition for the introduction of such a technique. Regarding a comparison between sectors, it may be remarked that inter-sector capital-labour ratios usually diverge, which has largely to do with a limited diffusion of techniques between sectors. This implies that, along with it, the average productive power of labour $\left(\mathrm{L}^{\alpha}\right)$ for each sector also diverges. All this implies that given some average intensity of labour $\left(\mathrm{L}^{\mathrm{i}}\right)$, we have the variables as set out in Table 4.3.

\section{TABLE 4.3 Stratification related intra- and inter-sector variables}

\section{Within sectors Between sectors}

\begin{tabular}{lll}
\hline technology and technique & diffusion & limited diffusion \\
$\mathrm{K} / \mathrm{L}$ ratios & divergent $^{*}$ & divergent \\
productive powers of labour $\left(\mathrm{L}^{\alpha}\right)$ & divergent $^{*}$ & divergent \\
rates of exploitation $(\mathrm{e}=\Pi / \mathrm{wL})$ & divergent $^{*}$ & divergent \\
rates of integral profit $\left(\omega_{\mathrm{t}}=\Pi_{\mathrm{t}} / \mathrm{K}_{\mathrm{t}^{\prime}}\right)$ & divergent $^{*}$ & tendential uniform
\end{tabular}

* Pending the diffusion.

14 Capital I, chapter 12 - chapter 10 of the German edition. 
Especially the diverging between-sector rates of exploitation have been a much-contested issue within marxian political economy. ${ }^{15}$ All this is amplified in Reuten 2017.

\section{$4 \S 5 \quad$ Instrumentality of the form of market interaction}

For enterprises, the form of market interaction (competition, cartels, monopolisation) is merely instrumental to their production and accumulation of capital. This does not mean that any individual enterprise has the choice of adopting any instrument such as competition or cartel formation. As indicated $(4 \S 1)$, in their market interaction, enterprises force the determinants of the capitalist system upon one another and upon themselves. Whilst any enterprise is a constituent of this enforcement, one or another form of market interaction may nevertheless be imposed on the enterprises. In internalising that form, or in complying with it, they impose that particular interaction on themselves and on the others. ${ }^{16}$ This means that we have distinct market constellations in which one particular form (competition, cartels, monopolisation) is dominant.

Even so, this does not imply that the impetus that might give rise to another form disappears altogether. Rather, in the mutual counteraction of the respective forces that gives rise to each of the forms, one force comes to manifestly dominate within a particular constellation. The other ones become subordinate or latent. We will see later on that the pace of process innovation (technical change) or of product innovation is one of the main forces that determine these constellations.

Divisions 2-3 present competitive constellations, Division 4 cartels, and Division 5 oligopolisation and monopolisation.

\section{Division 2. Deflationary price competition}

This division presents the first general mode of manifestation of the enterprises' market interaction. There are two main modes (or forms) of rivalrous interaction of enterprises (that is, forms of competition), each one based on the sector's enterprises' resignation to a rotating price-leader. The first general mode of 'deflationary price competition' is presented in the current division. The second general mode will be presented in the next division.

15 It is the main issue that is associated with the so-called 'transformation problem'.

16 In this case, that form of interaction constitutes a configuration in connection with the forces, 'the determinants of the capitalist system', developed earlier (Chapters $1-3$ ). The distinction between compliance and internalisation was set out in $2 \S 7$-b. 


\section{4§6 Stratified price competition: devalorisation via a decreasing 'unit monetary value of labour' (m) \\ Preliminary remarks}

We have seen that sectors of production tend to be composed of a stratification of plants $(4 \S 4)$. This is the basis for market interaction in general. I start the exposition with 'stratified price competition' (though note that I do not assume neoclassical equilibrium or so-called 'perfect' competition typified by homogeneous small-sized firms). We have also seen that in the absence of overcapacity, market prices will tend to stabilise at the existing level, whereas in the case of overcapacity it does make sense to initiate price decrease (4§3). At near to full capacity utilisation, price competition fades away. ${ }^{17}$ Hence effective price competition is conditioned by overcapacity. ${ }^{18}$

Reading the exposition below might be facilitated if the reader briefly reviews the terminology of $1 \S 14$ (especially that around equations $1.3-1.8$ ) - see, alternatively, the list of equations at the end of the book.

\section{Stratified price competition}

With competition, enterprises will try to eliminate competitors, or at least to make them fall behind. In a constellation of general price competition, the initiator of competitive action tends to combine:

- a technical advance (such that it might reduce prices);

- the creation of potential overcapacity in a market by investing in a new plant;

- actual price decrease (so as to effectively put behind or eliminate competitors).

It thus acts as price-leader - a function that might rotate between enterprises - setting the price at a level that maximises its profits. Given the technical advance and the production capacity of the price-leader, the other enterprises will tend to resign to the price-leadership. Explication $4 \S 6$-a sets this out in detail in reference to the stratification framework initiated in $4 \S 4$. Here I present the main thread.

So the initiator (i.e. the innovator) introduces a new technique. For its competitors, nothing changes in their techniques and the associated production power of labour $(\alpha$, more precisely $\alpha)$. Nevertheless, due to the market price decrease, the latter are in effect confronted with a devalorisation (a decreased

\footnotetext{
17 It might be argued that the threat of entry from relatively low rate of profit sectors $(4 \S 2)$ might induce price decrease. However, in the absence of any form of cartels $\left(4 \mathrm{D}_{4}\right)$, no enterprise has an interest in pre-empting this.

18 Cf. Clarke 1994, pp. 281-3.
} 
valorisation - on valorisation see $1 \S 10) \cdot{ }^{19}$ Its benchmark is the valorisation of the same capitals (enterprise, plant) in the previous period. This devalorisation is due to the actual monetary value of labour $\left(\mathrm{mL}^{\alpha}\right)$ for any single capital lagging behind that in the previous period. This applies not on the unchanged $L^{\alpha}$, but on a decrease in the ' $m$ ' (the unit monetary value of labour $-1 \S 14$, heading 6). For the initiator, on the other hand, the comparative rate of surplus-value increases, because of the relatively greater value-productivity of the labour employed in the plant added to the stratification (its $\alpha$ moves ahead of that of competitors). Thus, denoting the initiator by $(\mathrm{n}+1)$ and the previous priceleader by $(\mathrm{n}), \mathrm{mL}^{\alpha}{ }_{(\mathrm{n}+1)}>\mathrm{mL}^{\alpha}(\mathrm{n})$, for any ' $\mathrm{m}$ '. In fact $(\mathrm{n}+1)$ 's price decrease, means that ' $m$ ' decreases for the whole sector, making this itself good via its higher $\alpha$, such that its integral rate of profit $(\omega)$ is higher than that of (n) - and all competitors. The initiator's strategic consideration is that it introduces this new technique at the point when its price-decreasing action still secures a higher rate of profit for itself. The effect is that for all the competitors, the rate of integral profit decreases in comparison with the previous period (see further $4 \S 6-\mathrm{a}$ ).

Next to this devalorisation, and to the extent that plants from the bottom of the stratification are eliminated prior to their full amortisation, there is also an annihilation of previously accumulated capital.

I call this articulation of production and competition through time 'stratified price competition.'20

3

\section{Summing up}

So far, in sum, we have a tendency to equalisation of average inter-sector rates of profit $(4 \S 2)$, which, together with the tendency to uniform prices in a market $(4 \S 3)$, gives rise to an intra-sector stratification of plants with corresponding stratified rates of integral profit ( $4 \S 4)$. Stratified price competition, the addition to the stratification of new technique embodying plants, gives rise to price decrease and so devalorisation for the previous stratification and thus to a decline in the rate of profit for that previous stratification. ${ }^{21}$

19 Devalorisation refers to the value-added, and should be distinguished from depreciation, i.e. the (calculated) normal returns for the wear and tear of means of production $(\delta \mathrm{K})$.

20 It might also be called 'stratified dynamic price competition' (cf. Schumpeter 2003 [1943], pp. 103-4), who coined the term 'dynamic competition', in face of the taking into account of sequences of production periods.

21 Note that a rigorous product innovation may have the same result: scrapping of 'bottom' plants and of devalorisation. 
4§6-a Explication. Stratified price competition

This explication sets out some analytical details on which $4 \S 6$ is based. It builds on the framework introduced in $4 \S 4$-a. Most of the formulations of the second half of $4 \S 6$ have been integrated in this explication.

Capital invested in a new plant $(\mathrm{n}+1)$ and added to the stratification operates with up-to-date techniques of production - those with minimal unit costs of production and maximal value-productivity of labour $(4 \S 4)$. If $(n+1)$ were to undertake no further action (hypothetically), this investment would increase the total production capacity of the sector. The new investment is supposed to be one that potentially fully results in overcapacity of the stratification; this is the most transparent case - see Figure 4.4. (In a more complicated picture, we could account for degrees of extra capacity in relation to economic growth and effective demand. Macroeconomic demand effects of investment and scrapping will be presented in Chapter 5 . Another simplification is that the overcapacity created by $\mathrm{n}+1$ is assumed to be proportionally distributed over all plants).

In case of the currently presented $(4 \mathrm{D} 2)$ form of competitive interaction of enterprises, $(\mathrm{n}+1)$ anticipates the potential overcapacity (Figure 4.4) by price reduction. As a result, the plants at the bottom of the stratification that no longer cover prime costs will have to be scrapped (cf. $4 \S 4$ and $4 \S 4-\mathrm{a}$ ). We may suppose that the enterprise that added the new plant is the one to initiate the price competition, i.e. an effective price decrease. Hence this enterprise acts as price-leader - a leadership that might be rotating. Thus when plant $(\mathrm{n}+1)$ is added to the stratification $(1, \ldots, \mathrm{n})$, and when $\mathrm{h}$ plants are scrapped, the previous stratification $(1, \ldots, \mathrm{n})$ becomes $(1+\mathrm{h}, \ldots, \mathrm{n}, \mathrm{n}+1)$. (See Figure 4.5.)

(Note that the general employment effect depends on:

1. The scale of $n+1$, in comparison with the scales of the scrapped plants $h$;

2. The capital-labour ratios $(\mathrm{K} / \mathrm{L})$ of $\mathrm{n}+1$ in comparison with $\mathrm{h}$.

Chapter 5 presents the macroeconomic effect.)

Due to the price decrease, the revenue of the remaining part of the previous stratification $(1+\mathrm{h}, \ldots, \mathrm{n})$ decreases, whereas the revenue of the new stratification $(1+h, \ldots, n, n+1)$ typically increases with the average rate of growth (to keep the analysis concise, it is assumed that the share of the sector in the total economy remains constant). ${ }^{22}$ I call the decrease in revenue of the capitals in the previous stratification devalorisation (decreased valorisation). Its benchmark is

22 In case of (macroeconomic or sector) recession, the revenue may remain constant or decrease (see Chapter 5). Generally, one sector may, of course, grow above average. 
the valorisation of the same capitals in the previous period. The devalorisation is due to the actual monetary value of labour $\left(\mathrm{mL}^{\alpha}\right)$ for any one capital (enterprise, plant) lagging behind that in the previous period. ${ }^{23}$ Thus, because their investments, costs and production processes are unaffected, whilst revenue decreases (they have to share with $n+1$ ), the rate of integral profit of the capitals accumulated in the remaining part of the previous stratification $(1+\mathrm{h}, \ldots, \mathrm{n})$ decreases. $^{24}$

FIGURE 4.4 Stratification of plants after plant addition: hypothetical constellation prior to market interaction

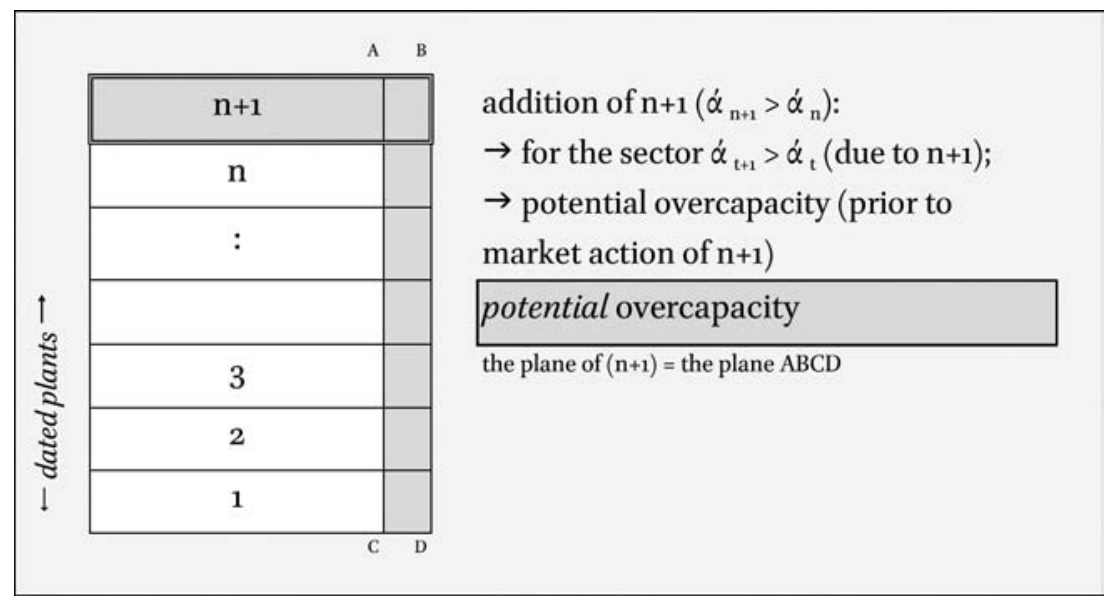

23 It might be argued that to the extent that devalorisation is foreseen at the point of investment, it is incorporated in calculating the 'marginal efficiency of capital'. But even if there were perfect foresight in this, the argument is unaffected. It cannot prevent devalorisation. Even with devalorisation, the net profits over the lifetime of the asset may still be positive and 'optimal'.

24 At the new price, the rate of profit of the capital invested in the new plant $(n+1)$ will tend to be above the average rate of profit of the capitals making up the previous stratification $(1, \ldots, n)$ at the previous price; or also above the rate of profit of the plant $(n)$ that was previously at the top of the stratification. In any case, since the new plant $(n+1)$ operates at lower costs and higher productivity than the previous plant $(n)$, the rate of profit of the new plant capital at the new price is above both that of the $\mathrm{n}^{\text {th }}$ and the average rate of profit. 
FIGURE 4.5 Stratification of plants after plant addition: actual constellation after price decrease, devalorisation and scrapping

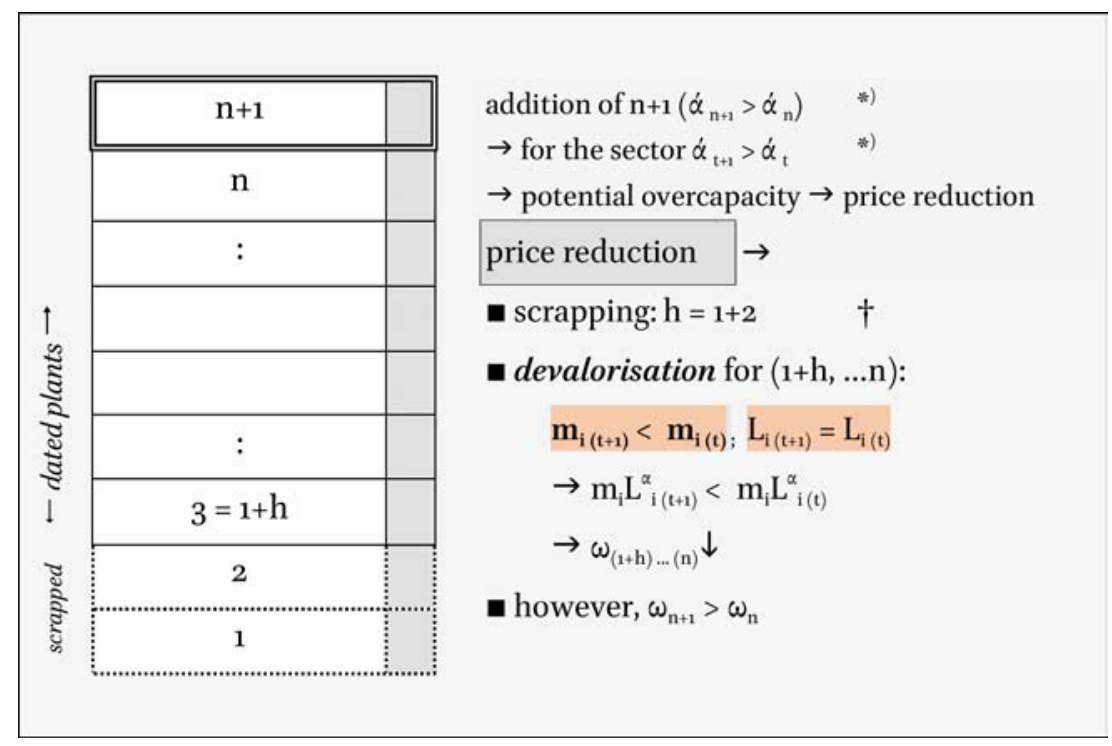

* Identical to Figure 4.4

$\dagger$ Scrapping of two plants instead of one assumes that plants grow in size (in case of equally sized plants $(1)-(n+1)$, only plant (1) would be scrapped)

In other words, because of the relatively greater actual monetary-valueproductivity of the labour employed in the plant added to the stratification $(\mathrm{n}+1)$, its comparative rate of surplus-value increases, whilst the actual monetary value of the labour in the $(1+h, \ldots, n)$ plants decreases (typically by a decrease in output prices). Therefore, not only is the 'unit monetary value of labour' $(1 \S 14$, heading 6$), \mathbf{m}_{\mathbf{i}}$, stratified increasingly from $(1, \ldots, \mathrm{i}, \ldots, \mathrm{n})$, but it also tends to decrease (devalorisation) for all i when the stratification is extended. ${ }^{25}$

In sum, stratified price competition is a form of accumulation of capital along with the driving out, from the bottom of the stratification, of plants belonging to competitors. To the extent that these plants are driven out prior to their full amortisation, there is an annihilation of previously accumulated capital.

25 If there were some collaboration between the enterprises then we might have the sequence price decrease, scrapping, price increase. However, in a pure competitive constellation, there is no mechanism to bring this about. Moreover, price increase is predicated on the definitive scrapping. Especially enterprises that operate several plants may keep latently the non-used plant - at least for some time. 
(Quite apart from the stratification introduced here, this is analogous to Schumpeter's 'creative destruction' (2003 [1943], ch. 7). Incidentally, Marx (1981 [1894], p. 265) cast this in terms of his famous phrase of 'neue Kombinationen' (new combinations) that inspired Schumpeter (1934 [1911].))

\section{$4 \$ 7 \quad$ Devalorisation accounted on devalued capital}

(At this point this section seems a detail. Its relevance will become clear in the next division.) The previous section (4§6) posited a decline in the rate of integral profit $(\omega)$ for the previous stratification $(h, \ldots n)$. This is based on the convention of historical (dated) accounting. Alternatively, enterprises (when they, through competition, have become aware of the stratification change) may immediately apply the alternative convention of current cost accounting (or present value or replacement value accounting). ${ }^{26}$ They then apply a devaluation of capital proportional to the difference between the historical value of their assets as compared with the assets purchase price of the innovator's technique. Hence via this pure balance sheet operation, their decreased profits due to devalorisation are accounted on the now devalued capital. This second convention is most often the practice today. Its dubbed 'advantage' is that the implied losses are not revealed in a permanent decline of the rate of profit, but rather in an immediate capital loss. ${ }^{27}$

Thus, depending on the accounting practice, devalorisation may be manifested either directly in a declined rate of profit or in an annihilation of capital accumulated. The net effect (the cash flow effect, i.e. the sum of depreciation allowances and profits) is the same.

\section{$4 \S 8 \quad$ Derived price decrease and derived devaluation of capital}

Generalised price competition gives rise to generalised price decrease. This implies that even if for specific sectors no new profit-increasing techniques are available, these are still affected by the technical change and price competition of other sectors.

This is so for the following reason. Consider an enterprise - currently producing at the bottom of the stratification of a sector A - which moves without

26 As Polak (1940, pp. 15-16) indicates, this accounting method was originally set out by Kovero in 1912 and by Schmidt in 1921.

27 We have for the integral rate of profit of any plant $\mathrm{i}$ :

$$
\omega_{\mathrm{t}}=\Pi_{\mathrm{t}} / \mathrm{K}_{\mathrm{t}^{\prime}}=\left[\left(\mathrm{mL}^{\alpha}\right)_{\mathrm{t}}-(\mathrm{wL})_{\mathrm{t}}\right] / \mathrm{K}_{\mathrm{t}^{\prime}}
$$

(1.6) plant version

When because of devalorisation ' $m$ ' decreases, the rate of profit decreases. The balance sheet operation referred to results in a devaluation of $\mathrm{K}$, such that $\omega$ remains about constant. 
innovating to the top $\left(\mathrm{n}^{\prime}\right)$ by merely duplicating the technique of the top plant (n). It buys the new plant and equipment inputs from a (composite) sector B in which there was technical change and price decrease along with it. Therefore the fixed capital outlay of the new plant $\left(n^{\prime}\right)$ in sector A which it buys from $B$ is nevertheless lower than that of $A^{\prime} s(n)$ - because $\left(n^{\prime}\right)$ can buy the identical plant at lower prices than (n) did - whence $\left(n^{\prime}\right)$ is in a position to decrease the sector A output price. Thus the competitive process and price decrease in sector $\mathrm{A}$ is predicated on technical change and competition elsewhere (B).

Again we have a devalorisation for the previous stratification (of A), in this case one that I call derived devalorisation. Again, depending on the accounting convention, the implied rate of profit decrease may alternatively be expressed as a derived devaluation of capital.

In sum, (primary) devalorisation/devaluation stems from changes in the labour process, induced by new technical change within the sector under consideration. Derived devalorisation/devaluation comes about by a mere price decrease due to process changes and price decreases in other sectors. However, this derived price decrease equally tends to multiply through the economy, thus developing into (further) general price deflation.

4§8-a Explication. Physical reproduction and reproduction of capital From a one-sided physical (use-value) approach, it might seem that the derived devaluation of capital does not affect the reproduction. Indeed, physical reproduction (that is, the number of units of output of a plant) need not be affected by the input price decrease because new means of production can be bought at the lower price. But this does not take away the fact that the accumulation of capital (or the valorisation potential) has decreased. This becomes obvious when a plant is wholly financed by loans: then the amortisation reserves may be sufficient to buy a new plant, but not to cancel the loans.

4§8-b Explication. Quality (or product) competition

So far the exposition of competition has been mainly phrased in terms of price competition. Along with it we have product (or quality) innovation and competition. For the (primary) devalorisation (and devaluation of capital), the distinction is not relevant because product competition has the same effect. This also applies for the derived devalorisation (or devaluation) with respect to producer goods since their quality increase has a cost of production decreasing effect. 
4§8-c Explication. Small business sector and services sector

Even if stratified competition is on average less prominent in sectors that are product-inherently supplied by small businesses and in much of the services sector, the latter are nevertheless affected by generalised deflation and particularly derived devalorisation/devaluation of capital.

\section{$4 \$ 9 \quad$ Generalised price competition and the pace of technical change: price deflation and the tendency to stagnation}

It was indicated in Chapter 2 that profit augmentation is limited by the possible increase in the intensity of labour, and that this limit is overcome by the investment of capital in technology and the application of technical change $(2 \S 2)$. Even if this is a high level determinant of the capitalist system, the pace of technical change is contingent. However, when this change is triggered such that its combination with price competition generally precludes the full amortisation of (modal) capital investments - as revealed in continuous devaluation of capital - and when this multiplies through the economy in the form of price deflation, then it develops into a system-destructive or at least paralysing force.

Insufficient amortisation implies that the general accumulation of capital is in some degree annihilated. Then the uncertainty about this annihilation (or the expectation of annihilation) tends to dampen investment. This is first revealed in a dampening of the pre-validating finance $(\mathrm{PVF})$ requested by enterprises and provided by banks $(3 \S 2)$. Thus the production of surplus-value dampens and so the part of surplus-value in the form of interest that accrues to banks dampens.

Further, and more specifically, for the PVF that is being provided, general price deflation implies that the redemption of the PVF is impeded. ${ }^{28}$ Note that an actual non-redemption in this case - we may call this the 'deflationary PVF gap' - is quite different from a non-redemption of the PVF due to savings (named RPVF in $3 \S 6$ ). In the latter case, savers may substitute for the non-redemption. In case of a deflationary PVF gap, there are no potential substituents, i.e. no potential non-bank financiers (for this gap). For those gaps there is a permanent increase in borrowing from banks. Ultimately this may outrun the securities that the enterprises can provide to the banks.

28 Although this is generally so, it is most obvious for the case in which the PVF is used for the purchase of fixed means of production. The depreciation $(\delta \mathrm{K})$ returns in many tranches, with each subsequent tranche being smaller than the earlier one because of the devaluation of capital. 
Thus the result is not only a decrease in the quantity of bank finance (PVF), but also an increase in its risk and uncertainty. Any likely risk premium that banks will put on the going interest rate will further dampen the investment.

As to the (other) remaining part of the PVF (i.e. the RPVF apart from the gap), that is, the part for which there are potential financiers in the form of bonds, general price deflation puts these potential financiers in a position of relative power. The point is that they can wait with substituting for the RPVF provided by banks - so improving their bargaining position - because with generalised price deflation the purchasing power of their credits with banks increases anyway. In other words, general price deflation empowers potential ex post financiers with the means of 'striking. This tends (ceteris paribus) to put an upward pressure on the 'real' rate of interest. (An actual strike increases the banks' risk, whence banks will increase the rate of interest. $)^{29}$

General price deflation brings on two subsidiary problems for enterprises. One is that normally wages tend to be sticky downwards (this may be different in crises and recessions; however, we are considering a structural constellation). A second, though temporary, problem is that the prospect of price decrease may have the effect of postponement of purchases of consumer durables as well as purchases of means of production in the branches with a relatively slower rate of technical change (e.g. services).

In conclusion, the combination of generalised speedy technical change (or a fast increasing pace of technical change) and generalised price deflation tends to generate stagnation. However, next to the deflationary constellation presented in the current division, an inflationary constellation $\left(4 \mathrm{D}_{3}\right)$ is also an implicit system possibility. Yet - recalling that Part One yet abstracts from (or brackets) the state and its economic policy - there are no economy-inherent forces that turn a deflationary constellation into an inflationary one. Further, there are no economy-inherent forces to get out of stagnation. ${ }^{30}$

4§9-a Amplification. The paradox of 'beneficial technical change' and 'beneficial competition' in combination

Both technical change and competition are often conceived of as beneficial features of the capitalist system (not least of all in ideological discourses; discourses in which, moreover, technical change is indiscriminately called 'tech-

29 Further, an increasing rate of interest means that shares (as compared with bonds) become inferior to financiers; this aggravates an inferiority of shares due to devaluation of capital.

3o In the systematic of this book, wars are contingent. 
nical progress'). However, it appears that prolonged fast technical change in combination with price competition does not fit the system.

4§9-b Addendum. The tendency of the rate of profit to fall in marxian political economy

Within one main strand of marxian political economy, an important theorem regards the 'tendency of the rate of profit to fall'. ${ }^{31}{ }^{32}$ Recalling that the exposition still has the state bracketed, a corollary of the main text of Division 2 is that the positing of such a tendency makes sense for a deflationary constellation with a generalised high pace of technical change. However, as we will see in the next division, that constellation cannot be generalised as a unique or dominant one for capitalism. That again does not imply that there could be no declining profit rate in the constellation that I present in Division 3. Generally, from my own perspective, the development of the profit rate is especially relevant as an indicator for the accumulation of capital.

Basu and Manolakos (2010; 2012), using data from Duménil and Lévy, show the long run secular movement of the rate of profit for the USA as reproduced in Graph 4.6. ${ }^{33}$

Note that Graph 4.6 inevitably shows the result of both structural and cyclical movements (the latter are presented in Chapter 5 ) as well as contingencies.

In reference to the dotted line that Basu and Manolakos plot (a Lowess trend), it is relevant that according to data for the USA from Piketty (2014, technical appendix), the period $1870-1913$ is on average deflationary (-0.7\%) and the period thereafter inflationary (for that period he provides for intervals of 20 to 37 years, average inflation rates of $2.2 \%$ to $5.6 \%$ - ending with $2.2 \%$ for the period 1990-2012). However, from Piketty's source (Piketty and Zucman 2013) it can be seen that the period $1921-33$ is on average highly deflationary $(-3.5 \%)$.

31 Roberts (2012) is a concise 13 pages paper with empirical findings (1963-2008 for the $\mathrm{G}_{7}$ ) and references to other empirical findings. It shows a sharply declining profit rate for $1963^{-}$ 1975, half of which recovers between 1975-1988, with next, until 2008, again a gradually bending down to the early 1970 level. https://thenextrecession.files.wordpress.com/2012/ og/a-world-rate-of-profit.pdf.

32 Regarding Marx's work I think that there is hardly a basis for this theorem in Marx's Capital if we neglect Engels' additions to that text - this is shown in Reuten 2004c. Nevertheless, there is a basis for it in Marx's manuscripts of before 1864 - as shown in Reuten and Thomas 2011. However, such a (non-)basis in Marx's work is irrelevant for the (in-)appropriateness of the research findings of current marxian political economy.

I am grateful to the authors for putting the graph at my disposal. 
Those two periods have been shaded in the graph. This shading merely puts the focus on one determinant - one that is focused on in Divisions 2 and 3 - among many others (see Chapter 5).

GRAPH 4.6 Long waves in the rate of profit: USA 1870-2007

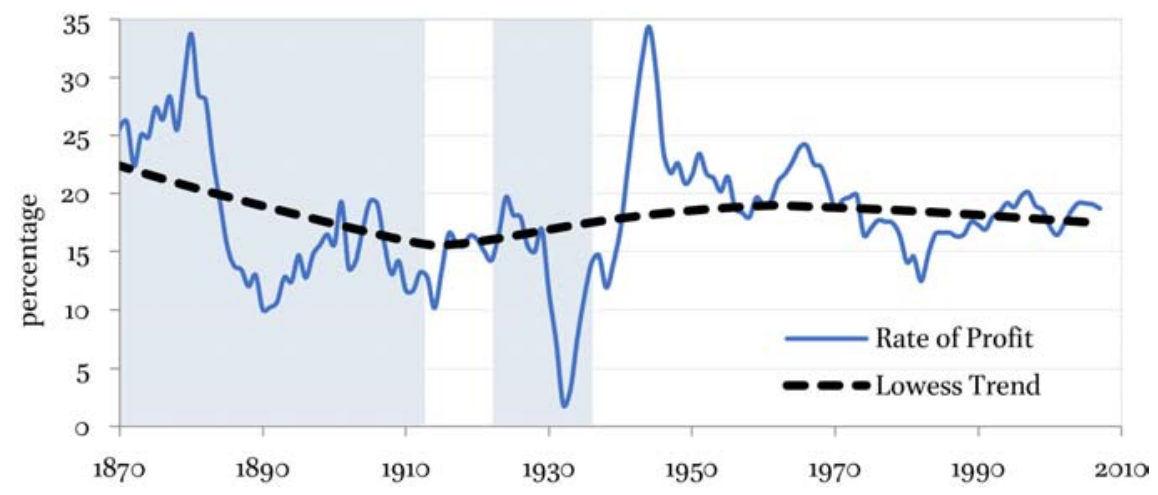

SOURCE: BASU AND MANOLAKOS (2010, P. 45), ON THE BASIS OF DATA FROM DUMÉNIL AND LÉVY (SHADING ADDED).

\section{Division 3. Inflationary 'structural overcapacity competition'}

This division presents the second general mode of manifestation of the enterprises market interaction. It is a competitive mode alternative to the one presented in Division 2. The current division does not set out how the economy goes from a deflationary to an inflationary constellation, because there are no economy-immanent forces to reach such a transition. ${ }^{34}$

Deflationary price competition is not difficult to understand - in mainstream economics, it is the prototype of competition. Understanding the mechanisms of inflationary competition is far more difficult.

\section{$4 \$ 10 \quad$ Overcapacity competition: introduction}

'Inflationary structural overcapacity competition' is a form of competition in which competitors are not eliminated by way of price decreases, but rather by burdening them with overcapacity. Overcapacity generally implies that, given the fixed cost (including especially those of fixed means of production

34 The state's efforts to prevent generalised price deflation are presented in $9 \S 5$ (and briefly anticipating that in $7 \S 8$ ). 
and overheads), unit cost increases in comparison with full capacity production. Production at overcapacity thereby results in decreasing revenue, whence marginal producers at the bottom of the stratification are forced out. Further details are presented in $4 \$ 12$.

Alternative names are 'structural excess capacity' or 'structural underutilisation of capacity'. ${ }^{35}$ It is to be emphasised that structural overcapacity is not the effect of market demand, but rather an overcapacity at any given demand. It is an overcapacity for market strategic reasons, at least so for the price-leader in a sector.

The constellation of prolonged fast technical change together with price competition, as presented in Division 2, is almost incompatible with the capitalist system. (By 'almost incompatible' I mean that the constellation engenders a tendency to stagnation.) The main reason is the primary and the derived devaluation of capital, set out in $4 \mathrm{D}_{2}(4 \S 6,4 \S 8)$. We have seen that this implies a degree of annihilation of the general accumulation of capital, and that this tends to dampen investment. We saw also that this affects not only production enterprises but also banks. For the latter it not only affects the quantity of their credit provision (PVF), but also their risk and uncertainty.

For these reasons, banks and production enterprises have a common interest in evading general price deflation. Although there is this common interest, there are no economy-immanent forces to bring it about (coordinated action would either presuppose the state, or a grand cartel via 'joint meetings' and decision making of captains of industry and banks, to which all others would have to comply).

The presentation below presupposes the existence of an inflationary constellation, in whatever way it is reached. There are two major conditions of existence for this constellation. The first one is presented in $4 \S 11$ and the second in $4 \S 12$.

35 The OECD glossary of statistical terms states: 'Excess capacity refers to a situation where a firm is producing at a lower scale of output than it has been designed for'. It adds: 'Excess capacity is a characteristic of natural monopoly or monopolistic competition'. Note that the current division broadens this considerably. It also adds: 'Firms may also choose to maintain excess capacity as a part of a deliberate strategy to deter or prevent entry of new firms'. This somewhat approaches the issue as presented in the current division, even if the focus will not be primarily on entrants but rather on squeezing out current producers. https://stats.oecd.org/glossary/detail.asp?ID=3209. 


\section{$4 \$ 11 \quad$ The monetary condition of an inflationary constellation: banks'PVF and the 'unit monetary value of labour' $(m)$}

One major condition for a constellation of generalised price inflation is the willingness of banks to accommodate that constellation via their credits to enterprises (PVF) as affecting the money in circulation. More specifically this has the effect of an increasing 'unit monetary value of labour' (m).

This accommodation has three further general effects. (Below any comparisons with a deflationary constellation are indented.)

In comparison with a deflationary constellation, banks now in effect accommodate a 'socialisation of private losses'. That is, they in effect socialise private losses that would be due to the devaluation of capital induced by technical change in the absence of price inflation. ${ }^{36}$ Relative to a deflationary constellation, price inflation results in an increased profit of enterprises and banks. ${ }^{37}$

First, its counterpart is a loss of purchasing power for social actors with nonequity financial assets (including 'small savers') and of actors with fixed incomes or with incomes that are (in part) adapted to inflation with a timelag.

Note that even a constellation of zero inflation makes quite a difference in comparison with some deflation, because it takes away the derived devaluation of capital $(4 \S 8) .38$

Second, inflation generates an actual derived revaluation of capital - the counterpart of the derived devaluation of capital presented in $4 \S 8$. This revaluation is expressed in the balance sheets of enterprises as capital 'reserves' (part of the equity).

Third, inflation puts employers (enterprises, including banking entities) in an advantageous bargaining position.

At a given, bargained, nominal wage, price decreases implied by labour productivity increase would automatically compensate labourers for the productivity increase.

36 The concept of socialisation of losses is set out in De Brunhoff (1978 [1976]) and derives initially (to my knowledge) from De Brunhoff and Cartelier (1974), though for each not in the context of devaluation of capital and competition. However, Aglietta (1979 [1976], pp. 313-15 and 365-70) theorises inflation in terms of 'anticipated obsolescence', which the current chapter connects to the structure of production (stratification).

37 For banks this is a matter of quantity and quality of the finance provided (as indicated above). Note that credits can be made 'inflation proof' for banks by flexible interest rates or by interest rate indexation.

38 In case of zero inflation there may still have been an accommodated socialisation of losses. 
In case of inflation, workers will have to re-bargain for the productivity compensation or even for a mere maintenance of the purchasing power of the initial wage. (In the case of partial or full compensation, these compensations tend to come about with a time-lag.)

\section{$4 \$ 12 \quad$ Stratified structural overcapacity competition}

Recall from the beginning of $4 \S 10$ that overcapacity competition involves the burdening of competitors with overcapacity, whence their unit costs increase in comparison with full capacity production. The second main condition of inflationary overcapacity competition (next to the one presented in $4 \S 11$ ) is generalised 'structural overcapacity'. It prevents a, continuously lurking, shift into a deflationary constellation. I present this constellation in three steps, starting with 'simple overcapacity'.

1

\section{Simple overcapacity: merely transitional overcapacity}

Similar to the constellation of price competition $(4 \mathrm{D} 2)$, stratified overcapacity competition is initiated by a (rotating) price-leader that has added a new plant to the stratification, which embodies a technical advance over its competitors. Again, this plant addition increases the (potential) total production capacity of the stratification. Now, however, the price-leader aims to squeeze out competitors from the bottom of the stratification not by price decrease as affecting their revenue, but rather by burdening them with overcapacity as affecting their revenue (their unit costs increase in comparison with full capacity production, because they continue to be burdened with the fixed cost, including especially those of fixed means of production and overheads). Thus the price-leader creates actual overcapacity in the sector (equivalent to the size of its own plant). Along with it, the aim is to increase the price, or to keep it at least constant. In order to keep the exposition concise, I present the analytical case of marginal inflation, that is, constant prices. Thus the price-leader sets a price equal to that of the previous period.

See $4 \S 6$-a, Figure 4.4 (plant addition). Now, however, read in that figure for 'potential overcapacity', 'actual overcapacity'. Figure 4.7 shows that situation with the bottom plants next having been scrapped (note that these plants were already operating marginally or near to it). This scrapping may not occur immediately, as at a constant output price these plants might be kept going for some time at merely a coverage of their prime costs $(4 \S 4$, penultimate paragraph $) .{ }^{39}$

[continued]

39 Their aim is to move to the top of the stratification (or near to it by merely copying the (n) or $(n+1)$ technique), as this increases their rate of integral profit. This is actualised in case there is no financial bottleneck. 
FIGURE 4.7 Stratification of plants with simple overcapacity (non-stable in case of marginal inflation)

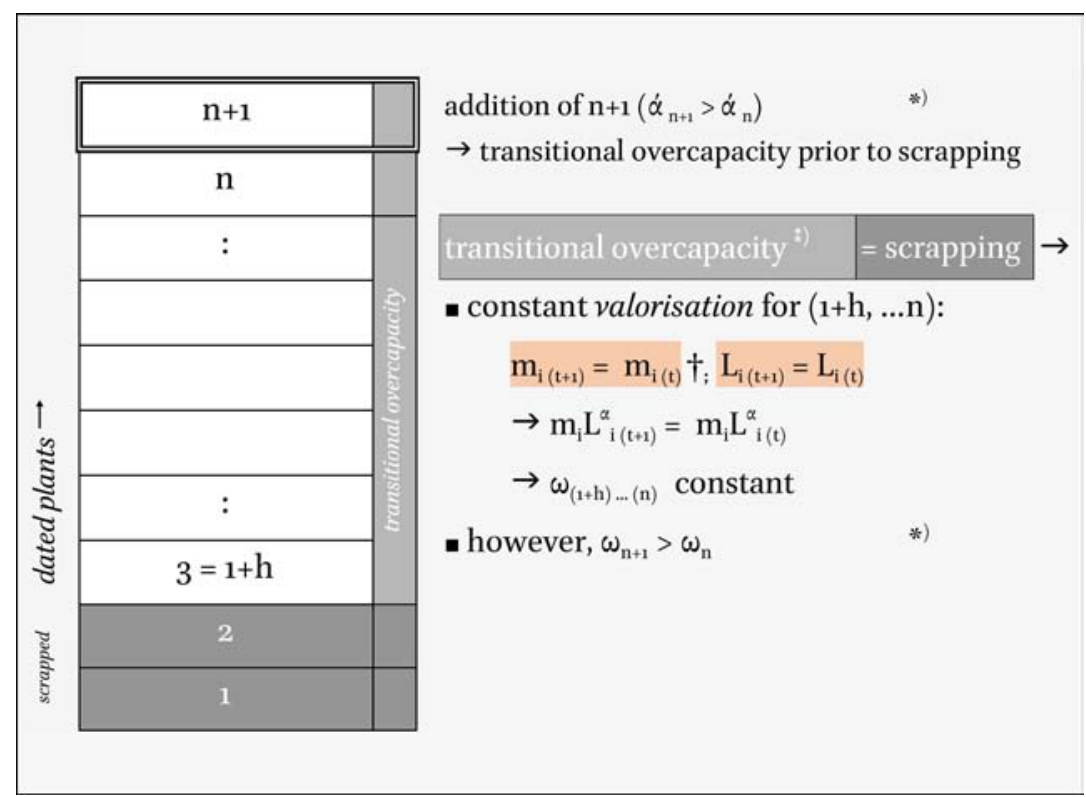

* Analogous to Figure 4.5 (deflationary price competition).

* Disappears after scrapping of bottom plants

$\dagger$ The equality applies for the analytical case of a constant price; in fact we have $m_{i(t+1)} \geq m_{i(t)}$

\section{$4 \S 12 \quad$ Continued}

\section{$2 \quad$ Structural overcapacity}

The following is relevant for marginal or low rates of price inflation and not so much for 'moderately high' rates (see Amplification $4 \S 12-b) .40$

So far an inflationary overcapacity-competition seems feasible on the basis of a constellation of a mere transitional 'simple overcapacity' as outlined above. However, considering Figure 4.7 it appears that such a constellation may not be stable (especially not on the edge of inflation - marginal inflation - that we are discussing; it might be more stable at higher levels of inflation). The point is that rotating price-leaders require an instrument to effectively respond to competitors that might contest their price-leadership via price decrease. This

40 Theoretically, it cannot be pinpointed what the relevant borderline is between 'low' and 'moderately high' rates. Perhaps the borderline is at around a rate of $4 \%$ price inflation. 
instrument is a structural overcapacity. That is, overcapacity beyond the transitional overcapacity. When the price-leader $(n+1)$ has a structural overcapacity, it is in the position to immediately respond to contesters (such competitors know that a, further, price decrease by the price-leader will immediately take away a large part of their market share). Because the price-leader must have a structural overcapacity, it will keep on having this overcapacity when in the course of time it moves down the stratification (its top position having been taken over by a new price-leader). Therefore, once an inflationary constellation is vested, all plants will tend to operate at a structural overcapacity. (See Figure 4.8. $)^{41}$

Stratified overcapacity competition via 'transitional extra overcapacity' beyond 'structural overcapacity'

With competition, enterprises will try to eliminate competitors, or at least to make them fall behind. In a constellation of structural-overcapacity competition, the initiator of competitive action tends to combine:

- production at structural overcapacity (like all the competitors - see heading 2 above);

- a technical advance (such that it might effectively reduce the price in case a contestation of its price-leadership would make price reduction necessary see heading 2 above);

- the creation of transitory extra overcapacity, such that it might take over the market share of competitors down the stratification (this extra overcapacity is equal to the potential production of the plant that was added, net of its structural overcapacity); after the bottom plant(s) is (are) scrapped, all of the extra overcapacity disappears. (See Figure 4.9, which is further expanded on below.)

It so acts as price-leader - a function that might rotate between enterprises setting the price at a level that maximises its profits. Given the technical advance and the structural overcapacity of the price-leader, the other enterprises will tend to resign to the price-leadership.

With generalised price inflation ' $m$ ' (interpreted as the price or price index of NDP) changes roughly in the same direction and the same pace as the prices of means of production. As indicated above, to keep the presentation transparent and concise, I present the case of marginal inflation, that is, constant

41 Depending on the particular sector and its technique of production, the size of a plant may be somewhat flexible. In that case plants down the stratification, which speculate that there will be no longer price competition, might downsize their plant. This does not apply to the upper plants. 
prices and a constant 'unit monetary value of labour' (m). (This is empirically relevant - see Explication $4 \S 12$-b.) Thus the price-leader sets a price equal to that of the previous period. I denote the initiator/price-leader and its plant added to the stratification by $(n+1)$. We may assume that the expected effect of this investment, especially on its integral profit and rate of integral profit $(\omega)$, has been taken into account prior to the investment in the top plant.

As a result of the transitory extra capacity $(n+1)$, and given the demand for this sector's output, the revenues for all plants in the previous stratification initially decrease (devalorisation), tantamount to this overcapacity. (See Figure 4.9.) As a result the plants (1...h) at the bottom of the stratification produce at marginal or zero profit, and will be scrapped. ${ }^{42}$ The result is that the extra capacity (not the structural overcapacity) is undone.

The total result (that is, pending the exposition of Chapter 5 ) is that for the remaining plants of the previous stratification $(1+h \ldots n)$, the conditions are similar to that of the previous production period. This includes equal (rates of) integral profit. In comparison with the constellation of price competition this is due to the inflationary 'socialisation of private losses' $(4 \$ 11)$. Note that from the perspective of enterprises, the structural overcapacity is in fact a 'desired overcapacity' (a term that will frequently be used in Chapter 5).

I end this section with two remarks. First, as with the deflationary constellation, the pace of technical change is important. Speeded up technical change and investment in new plants may mean insufficient amortisation of the plants at the bottom of the stratification, whereby for these the accumulation of capital is in some degree annihilated (with effect on the environment, including the climate and natural resources - cf. $4 \S 12-\mathrm{a})$. Independently of these effects on the bottom of the stratification, the question as to whether there is also a macroeconomic annihilation of capital accumulated depends on the combination of the speed of technical change and the inflationary 'derived revaluation of capital' referred to in $4 \S 11$.

Secondly, as with the deflationary constellation, the general employment effect of the inflationary constellation depends on: the scale of $n+1$, in comparison with the scales of the scrapped plants $h$; together with the capital-labour ratios $(K / L)$ of $n+1$ in comparison with $h$. (Chapter 5 presents the macroeconomic effect.)

42 Ineglect that, for strategic reasons, these bottom plants might be kept going for some time, producing at prime costs. In that case the end result would be reached in a subsequent production period. 
FIGURE 4.8 Stratification of plants with structural overcapacity

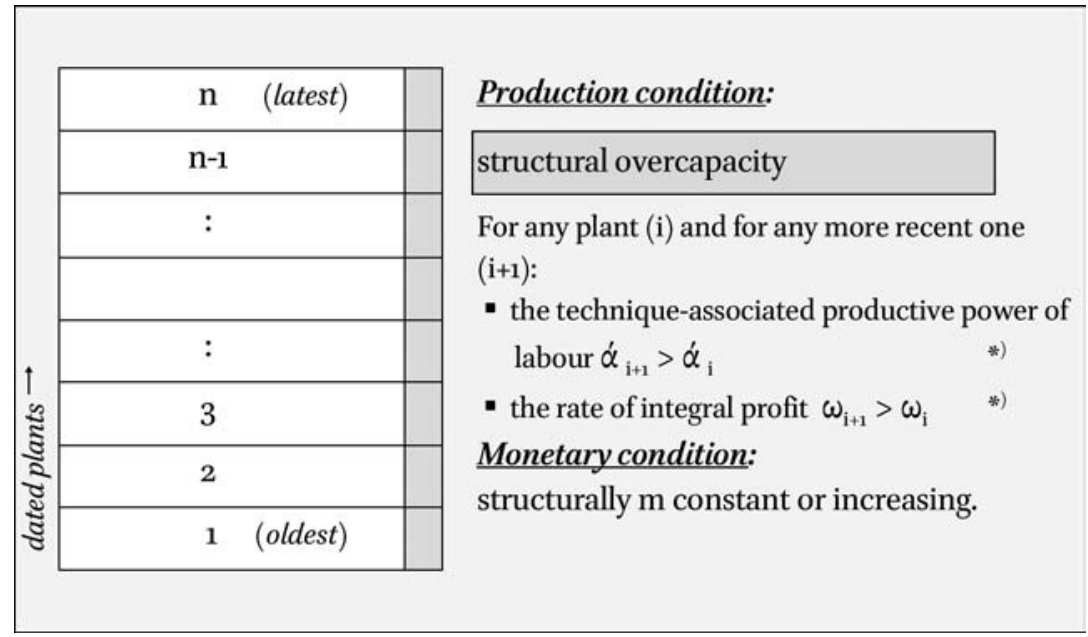

* Analogous to Figure 4.5 (deflationary price competition), though now with structural overcapacity

4§12-a Amplification. Continuous overcapacity and 'efficiency'

The term 'efficiency' is never a neutral one, and should always be specified as to the efficiency criterion. From the point of view of the climate, environment and natural resources, continuous overcapacity is not efficient. From the point of view of the generation of surplus-value for and the accumulation of capital of enterprises, it is efficient.

4§12-b Amplification. Merely transitory versus transitory-cum-structural overcapacity: the degree of inflation and the measurement of overcapacity

The measurement of overcapacity in a sector is not an easy matter, as such measurement is dependent on questionnaires among enterprises that for market-strategic reasons may not be keen to disclose the relevant information. Recall that the main section made a distinction between transitional 'simple overcapacity' and 'structural overcapacity'. It was indicated that the former tends to be unstable in the case of marginal or low rates of price inflation, and that it tends to be more stable at higher rates of inflation. This means that we can expect structural overcapacity to occur at especially 'low' rates of price inflation (perhaps a range of rates from o to $4 \%$ ?) and a merely transitional overcapacity at higher rates (below called the upper range). In the latter case, enterprises might not mention this, even if they are upfront in questionnaires. 
FIGURE 4.9 Stratification with structural overcapacity: marginal inflation

$\Delta m=0$

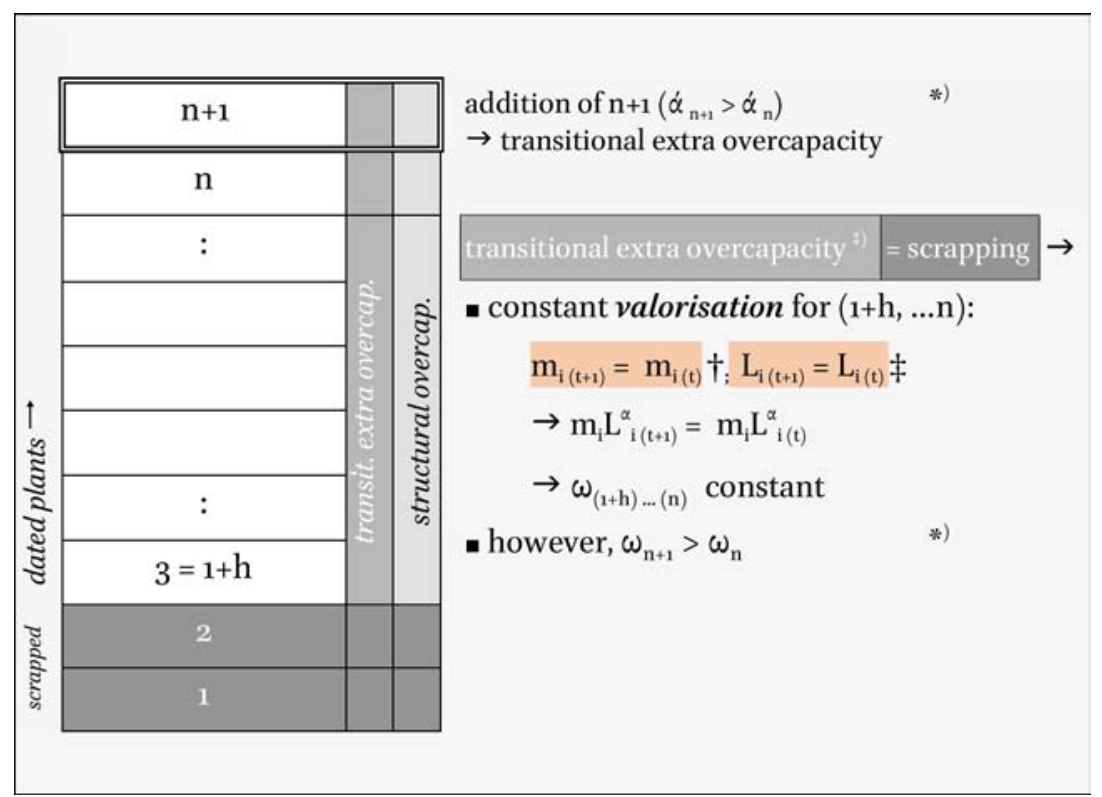

* Analogous to Figure 4.5 (deflationary price competition), though now with structural overcapacity.

* Disappears after scrapping of bottom plants.

$\dagger$ The equality applies to the analytical case of a constant price; in fact we have $m_{i(t+1)} \geq m_{i(t)}$.

‡ This full row indicates the main difference between the inflationary and the deflationary constellation (cf. Figure 4.5 for the latter).

The point about the upper range is that within it there could be recurrently some degree of price competition within some sectors (contesting the priceleadership) without falling into generalised deflation. Should it tend to more structured price wars, then the price-leader will build up structural overcapacity (like in the lower inflation range).

4§12-c Addendum. Kalecki and kaleckians on overcapacity

Kalecki suggested that there is on average a structural overcapacity: 'Even on the average the degree of utilization [of equipment] throughout the business cycle will be substantially below the maximum reached during the boom' (1971 [19431] , p. 137, see also his 2003 [1954], pp. 129-31). Ever since, there has been a controversy about this matter among heterodox economists. (See Lavoie 2014, ch. 6 , who provides a thorough review of this controversy.) Its context is mainly the business cycle, and in this context that is an important matter (see also Chapter 5). 
However, the current $4 \mathrm{D}_{3}$ does not (directly) intervene in that debate. My concern has been to understand the constellation of inflationary competition. It is rather in that context that structural overcapacity seems plausible, especially at marginal or moderate rates of price inflation.

\section{Division 4. The tendency to cartel formation}

This division presents a third, and particular, mode of manifestation of the enterprises' market interaction. Please refer to the outline of Scheme 4.1 about the systematic of the current chapter. The previous two divisions presented two alternative (and perhaps alternate) general constellations of competition. Divisions 4 and 5 present two particular modes of manifestation that coexist with each of the earlier general modes of manifestation (those of Divisions 2 and 3 ). Within each of these modes of manifestation, enterprises seek - in some way and to some degree - to overcome the rivalry associated with the competitive constellations. For Divisions 4 and 5 in particular, the reader is reminded once again that the state, and regulation by the state, has not yet entered into the exposition.

\section{$4 \$ 13$ The tendency to cartel formation: stagnant innovation}

Cartel formation may contingently occur in various circumstances. I emphasise that in this section I restrict myself to its impetus as related to the stratified structure of production and to innovation.

Range of the stratification of production

The frequency of the innovation in a sector of production (be it process or product innovation) determines the 'range' of the stratification - the range being the difference in the value-productivity of labour between the top and the bottom of the stratification (that is, the number of layers; several enterprises/plants may operate at the same layer - see Figure 4.10). In sectors where innovation is stagnant, the range of the stratification narrows down. This implies that it will be more difficult, and in the end impossible, for the top plant to induce the scrapping of bottom plants.

2

Stagnant innovation and the tendency to cartel formation

The more or the longer innovation slackens, the more time the bottom and medium plants will have to more or less copy the technique or the product of the top plant. Competition then approaches stagnant competition (somewhat similar to neoclassical static competition). Stagnant innovation and stagnant 
competition clear the ground for cartel formation. ${ }^{43}$ The object of a cartel is most often the fixing of prices. ${ }^{44}$

In stagnant sectors cartels, as based on firm agreements between enterprises, tend to be restricted to such sectors with a moderate number of enterprises supplying the commodity at hand. The reason is that agreements are difficult to maintain when a large number of enterprises operates in a sector. ${ }^{45}$

When the number of enterprises in a stagnant sector is relatively abundant, cartels tend to be implicit ones, taking the form of a tacit price-leadership.

Although cartels maintain profits higher than in the absence of the cartel, 'too' high profits might evoke entry into the sector. However, entry into a technically stagnant sector is hardly attractive for entrants.

$4 § 13$-a Explication. The range and density of the stratification of production

It has been implicit so far that a stratification of production is not only characterised by some range (the number of layers), but also some density (the number of plants at the same level) - see Figure 4.10. However, plant addition to the top of the stratification $(n+1)$ tends to be accomplished by a single innovator. Later on other enterprises may move to the top by more or less copying the technique of the innovator.

43 As indicated, this division is restricted to cartel formation related to the stratified structure of production and to innovation. Cartels also have advantages to enterprises with dynamic innovation.

44 'The most common practices employed by cartels in maintaining and enforcing their industry's monopoly position include the fixing of prices, the allocation of sales quotas or exclusive sales territories and productive activities among members, the guarantee of minimum profit to each member, and agreements on the conditions of sale, rebates, discounts, and terms.' (Editors Encyclopaedia Brtittanica, 'Cartels') https://www.britannica .com/topic/cartel - accessed 17 September 2016.

45 See also Ivaldi, Jullien, Rey, Seabright and Tirole (2003, p. 32) and Europe Economics (2001). The latter research institute mentions few firms, stable market conditions, and 'mature market with low innovation and low uncertainty' as conditions for collusion (p. 120; cf. pp. 27, 71-2 and 79). 
FIGURE 4.10 Stratification of production: range and density at each point in time

\begin{tabular}{|c|c|c|c|c|c|}
\hline $\mathrm{n}_{1}$ & $\mathrm{n}_{2}$ & $\ldots$ & $\mathrm{n}_{\mathrm{j}}$ & $\ldots$ & $\mathrm{n}_{\mathrm{m}}$ \\
\hline $\mathrm{n}-\mathbf{1}_{1}$ & $\mathrm{n}-\mathrm{1}_{2}$ & $\ldots$ & $\mathrm{n}-\mathbf{1}_{\mathrm{j}}$ & $\ldots$ & $\mathrm{n}-\mathbf{1}_{\mathrm{m}}$ \\
\hline : & : & & : & & : \\
\hline $\mathrm{i}_{1}$ & $\mathrm{i}_{2}$ & $\ldots$ & $i_{j}$ & $\ldots$ & $\mathrm{i}_{\mathrm{m}}$ \\
\hline : & : & & : & & : \\
\hline $2_{1}$ & $2_{2}$ & $\ldots$ & $2_{j}$ & $\ldots$ & $2_{\mathrm{m}}$ \\
\hline $1_{1}$ & $1_{2}$ & $\ldots$ & $1_{j}$ & $\ldots$ & $1_{\mathrm{m}}$ \\
\hline
\end{tabular}

4\$13-b Amplification. Agreements regarding tenders and market sharing Independently of the make-up of the stratification of production, there is also a tendency to collaboration in case of recurrent tenders for big projects (ranging from construction to ICT). In this case the enterprises provide each other with information about their offer (all but one make a fake offer), so as to reach market sharing. This market sharing is generally more likely when a market is oligopolistic.

4§13-c Addendum. Adam Smith on cartel formation: conspiracy The phenomenon of cartels of enterprise is as old as the early emergence of capitalism. In 1776, Adam Smith wrote: 'People of the same trade seldom meet together, even for merriment and diversion, but the conversation ends in a conspiracy against the public, or in some contrivance to raise prices' (Book I, Ch. 10, section 82$) .46$

\section{Division 5. The tendency to oligopolisation and monopolisation}

This division presents a fourth, and particular, mode of manifestation of the enterprises' market interaction. Like Division 4 it is particular in that it coex-

46 He continues: 'It is impossible indeed to prevent such meetings, by any law which either could be executed, or would be consistent with liberty and justice. But though the law cannot hinder people of the same trade from sometimes assembling together, it ought to do nothing to facilitate such assemblies; much less to render them necessary' (cf. Book I, Ch. 8, sections 12-13 on 'combinations' not to raise wages). 
ists with either a deflationary or an inflationary constellation. Although this is a brief division (one section), the content is far-reaching in its effects. The tendency outlined in this division is presented purely from the perspective of the capitalist economy. (See Chapter 9 about the involvement of the state.)

\section{$4 \$ 14 \quad$ The tendency to centralisation of capital}

\section{$1 \quad$ Centralisation of capital}

The particular market interaction is a mere instrument for the profit-making of enterprises $(4 \S 5)$. This equally applies to the two competition extinguishing forms of market interaction, one of which is the merging of fellow enterprises within a sector, that is, the vesting of some degree of centralisation of capital. The other is the take-over form of centralisation. The ultimate form of centralisation of capital is that of vesting oligopolies and next a monopoly in a market. ${ }^{47}$

\section{Oligopolistic sectors: capital-labour ratio and scale}

Although mergers and take-overs are a general phenomenon, there is a tendency to centralisation of capital particularly in sectors with, first, a relatively high capital-labour ratio $(\mathrm{K} / \mathrm{L})$, and secondly, when extra surplus-value can be gained from a large scale $(\mathrm{K}){ }^{48}$ This applies to a large variety of sectors, ranging from the production of energy, agricultural seeds, means of transport (cars, trains, aeroplanes), industrial intermediates (steel, aluminium), means of communication, pharmaceuticals, to banking and insurance. The larger the scale grows, the more the entrance to the sector is precluded (and if there is entrance, this tends to be from the part of conglomerating oligopolies).$^{49}$

As with the general constellations of competition $\left(4 \mathrm{D}_{2}\right.$ and $\left.4 \mathrm{D}_{3}\right)$, one enterprise tends to act as price-leader (tacit or agreed). In this case, however, the effective range of the stratification tends to be such that each oligopolistic enterprise operates at all levels of the stratification, which, in comparison with (full) competitive sectors, may be a relatively small ranged one. To the extent

More precisely, this is the penultimate form of centralisation of capital. The ultimate shape of centralisation is the centralisation of all capital in one inter-sector monopoly.

48 This is a particular case of increasing returns to scale.

49 For example, an oligopolistic pharmaceutical enterprise may, by way of a merging conglomeration, enter the oligopolistic agricultural seeds sector (the case of Bayer initiated in 2016). 
that oligopolistic enterprises have an about even production and market power (spread over their plants), they tend to evade price competition and to restrict to capacity competition. ${ }^{50}$

\section{$4 \quad$ Monopolisation}

To the extent that, within an oligopolistic sector, a further centralisation via mergers or take-overs creates a new unevenness in power within that sector, this may temporarily reinforce the rivalry for the vesting of a price-leadership and next reinforce mergers of competing oligopolies. In this way the centralisation of capital tends to develop into a self-reinforcing process: centralising actions within a sector tend to evoke centralising actions by other enterprises so as to counteract the shift in the balance of power. When the result of such a series of mergers is a duopoly with uneven production and market power, then their merging into a monopoly tends to be the final outcome. ${ }^{51}$

From the perspective of the enterprise, the 'centralisation of capital', and hence the limitation or exclusion of competition, is in line with the (from their perspective) 'rational' optimal profit-seeking. All along the criterion for these (and other) enterprises is the rate of integral profit ( 1 §13). The form of oligopoly and monopoly seems frightening for many. However, more threatening to the capitalist system is that it openly puts the 'why' of the criterion on the agenda.

6

Counteraction of the tendency to average inter-sector equalisation of profit rates

For all these constellations it holds that - as long as sectors of production are unevenly populated by oligopolies (and monopolies) - the joint market power within a sector results in prices above competitive prices $\left(4 \mathrm{D}_{2}, 4 \mathrm{D}_{3}\right)$, which affects the costs for other sectors, and ultimately the prices of consumer goods. This unevenness, together with the entrance impediments referred to, counteracts the tendency to average inter-sector equalisation of rates of profit $(4 \S 2)$.

50 It is often argued that oligopolies 'compete' in terms of product differentiation. This argument is fine as far as it goes. Either such differentiation is negligible in terms of the oligopolies constituting a market; or it is effective whence we in fact have a constellation of monopolies in single markets. (Cf. $4 \S 3$-a on intra-market interaction and product differentiation.)

$5^{1}$ Recall again that the state is still bracketed at this stage. To the extent that the state prevents monopolisation, a powerful oligopolistic enterprise may allow a weaker one to continue operating. 
4§14-a Amplification. Centralisation of capital and the monetary value of labour

Recall from $1 \S 14$ that the valorising exertion of labour is measured as valueadded: $m L^{\alpha}$, with the surplus-value being measured as $\mathrm{mL}^{\alpha}-\mathrm{wL}$. This applies both macro- and microeconomically.

To the extent that centralisation of capital is technique related - that is, along with relatively high capital to labour ratios $(\mathrm{K} / \mathrm{L})$ and large scale $(\mathrm{K})$ - the productive power of labour $\left(\mathrm{L}^{\alpha}\right)$ increases concomitantly. However, when on top of the technique related centralisation, centralised enterprises (oligopolies or monopolies) also gain extra profits from market power, these profits do not stem from labours' productive power $\left(\mathrm{L}^{\alpha}\right)$, but rather from the unit monetary value of labour $(\mathrm{m}) .^{52}$ Empirically the two $\left(\mathrm{L}^{\alpha}\right.$ and $\mathrm{m}$ ) are not distinguishable (we can measure just value-added, $\mathrm{mL}^{\alpha}$, and regarding surplus-value the latter minus wages). More precisely, they are directly indistinguishable. Indirectly, the two can be distinguished via average inter-sector equalisation of rates of integral profit. That is, when in a sector the average rate of integral profit is structurally above the total economy's rate of integral profit, we can infer that this stems from between-sectors differing market power positions as reflected in a between-sectors diverging unit monetary value of labour $(\mathrm{m})$.

That we can measure this only indirectly is a shortcoming, even if similar ones also apply to many accepted theories in the social and natural sciences.

A similar indirect measurement relates to cartels $(4 \S 13)$. However, without additional information about the structure of sectors, this would mean that cartel formation and centralisation power are difficult to separate.

\section{Summary and conclusions}

Rather than presenting conditions of existence of the earlier exposition (Chapters 1-3), this chapter has set out the concrete manifestation of the earlier exposition in the market interaction between enterprises.

Division 1 set out how the interaction of enterprises gives rise to the intermarket tendency to equalisation of average inter-market rates of integral profit, and the intra-market tendency to uniform prices $(4 \S 2-4 \S 3)$. The articulation of these tendencies implies that the rate of integral profit of any one enterprise comes to depend on its production. To the extent that the structure of

$5^{2}$ I stick to the term 'unit monetary value of labour' because without labour's production, there would be no production at all (1§14) and hence also no gains from market power. 
production is dynamic, as measured by the degree of technical change or other innovation, enterprises in a market - particularly their plants - tend to be stratified as to the production power of labour and concomitant rates of integral profit $(4 \S 4)$.

On the basis of this framework of the stratification of enterprises, Divisions 2-5 presented four main forms of the market interaction between enterprises.

Division 2 set out, what was called, 'deflationary price competition'. Depending on the degree of process and product innovation, price competition tends to result in a combined accumulation and devaluation of capital $(4 \S 6-4 \S 7)$. Generalised price competition gives rise to deflationary generalised price decrease. Price decreases then affect not only the sector at hand, but also the input prices of other sectors and again their stratification, whence we have a derived devaluation of capital (4§8). It was indicated how the combination of generalised fast technical change (or a fast increasing technical change) and generalised price deflation tends to generate stagnation. There are no economyinherent forces to get out of such stagnation $(4 \S 9)$.

Division 3 presented the alternative competitive constellation of 'inflationary structural overcapacity competition'. In terms of effects, the main distinction with the deflationary constellation is that it leaves undone not only price decreases in the sector at hand, but also its multiplication throughout the economy via input prices (i.e. the derived devaluation of capital). It was indicated that within this constellation (pending the exposition of Chapter 5), enterprises may over time maintain their integral rate of profit. However, depending on the pace of technical change, this may go along with insufficient amortisation (hence a degree of annihilation of previously accumulated capital) for enterprises successively operating at the bottom of the stratification - with effect on the environment including natural resources $(4 \S 12)$.

It was also indicated in this division that the just mentioned maintenance of the rate of integral profit is (in comparison with deflationary price competition) the effect of 'inflationary socialisation of losses' due to the banks' accommodation of inflation. The counterpart of the comparative profits deriving from it are in a loss of purchasing power for social actors with non-equity financial assets (including 'small savers'), for actors with fixed incomes or with incomes that are (in part) adapted to inflation with a time-lag, the latter including workers who will have to re-bargain for the productivity compensation or even for a mere maintenance of the purchasing power of the initial wage $(4 \S 11)$.

Divisions 4 and 5 presented two particular constellations that coexist with each of the earlier general constellations. Within each of these constellations, enterprises seek to, in some way and to some extent, overcome the rivalry that is associated with the competitive constellations. 
Whereas Divisions 2-3 presented the enterprises' interaction in dynamic sectors and their markets - that is, the sectors in which innovation is flourishing - Division 4 turned to sectors and their markets that are stagnant in terms of innovation. In such sectors, competition fades away and clears the ground for cartel formation of enterprises.

Division 5 presented a final form of market interaction: the centralisation of capital via mergers and take-overs giving rise to oligopolisation and monopolisation. Such centralisation is particularly prevalent in sectors producing at relatively high capital-labour ratios together with a large scale of capital. Centralising actions within a sector tend to evoke centralising actions by other enterprises, whence centralisation is a self-reinforcing process. The final form of centralisation is the vesting of a monopoly in a market. Centralisation (as long as it is unevenly distributed over sectors) counteracts the tendency to equalisation of inter-market rates of integral profit $(4 \$ 2)$. The joint market power within a sector concomitant with this centralisation results in prices above competitive prices $\left(4 \mathrm{D}_{2}, 4 \mathrm{D}_{3}\right)$, which affects the costs for other sectors, and ultimately the prices of consumer goods.

\section{List of figures chapter 4}

Scheme 4.1 Market interaction and the stratified structure of production: competition cartel formation, oligopolisation and monopolisation (Outline Chapter 4) 202

4\$4. Stratification of enterprises and plants

Figure $4.2 \quad$ Stratification of plants 211

Table 4.3 Stratification related intra-and inter-sector variables 213

4§6. Stratified price competition: devalorisation via a decreasing 'unit monetary value of labour'

Figure 4.4 Stratification of plants after plant addition: hypothetical constellation prior to market interaction 218

Figure 4.5 Stratification of plants after plant addition: actual constellation after price decrease, devalorisation and scrapping 219

4§9. Generalised price competition and the pace of technical change: price deflation and the tendency to stagnation

Graph 4.6 Long waves in the rate of profit: USA 1870-2007 225 
$4 \S 12$. Stratified structural overcapacity competition

Figure 4.7 Stratification of plants with simple overcapacity (non-stable in case of marginal inflation) 229

Figure 4.8 Stratification of plants with structural overcapacity 232

Figure 4.9 Stratification with structural overcapacity: marginal inflation $\Delta m=0 \quad 233$

4\$13. The tendency to cartel formation: stagnant innovation

Figure 4.10 Stratification of production: range and density at each point in time $\quad 236$ 